\title{
Functional aspects of primary cilia in signaling, cell cycle and tumorigenesis
}

Sander G Basten ${ }^{1,2}$ and Rachel H Giles ${ }^{2 *}$

\begin{abstract}
Dysfunctional cilia underlie a broad range of cellular and tissue phenotypes and can eventually result in the development of ciliopathies: pathologically diverse diseases that range from clinically mild to highly complex and severe multi-organ failure syndromes incompatible with neonatal life. Given that virtually all cells of the human body have the capacity to generate cilia, it is likely that clinical manifestations attributed to ciliary dysfunction will increase in the years to come. Disputed but nevertheless enigmatic is the notion that at least a subset of tumor phenotypes fit within the ciliopathy disease spectrum and that cilia loss may be required for tumor progression. Contending for the centrosome renders ciliation and cell division mutually exclusive; a regulated tipping of balance promotes either process. The mechanisms involved, however, are complex. If the hypothesis that tumorigenesis results from dysfunctional cilia is true, then why do the classic ciliopathies only show limited hyperplasia at best? Although disassembly of the cilium is a prerequisite for cell proliferation, it does not intrinsically drive tumorigenesis per se. Alternatively, we will explore the emerging evidence suggesting that some tumors depend on ciliary signaling. After reviewing the structure, genesis and signaling of cilia, the various ciliopathy syndromes and their genetics, we discuss the current debate of tumorigenesis as a ciliopathy spectrum defect, and describe recent advances in this fascinating field.
\end{abstract}

Keywords: Cilia, Signal transduction, Cell cycle, Cancer

\section{Review}

\section{Ciliogenesis}

Once a cell enters quiescence, it must go through a series of events to realize a fully matured cilium. All cilia subtypes must conform to a basic structure. The elemental cilium is composed of the basal body (BB) that is located at the apical plasma membrane, and an axoneme that forms a thin projection extending from the membrane (Figure 1) [1]. The BB is derived from the centrosome and comprises a mature centriole, accessorized by sub-distal appendages, connected to an immature centriole that is surrounded by a dense protein-rich pericentriolar matrix [2]. In early ciliogenesis, a golgi-derived ciliary vesicle fuses with the $\mathrm{BB}$ at the distal side of the mature centriole that features the appendages and CEP164 seems to act as the principal linker between the centriole and ciliary vesicle [3]. After the basal body has migrated to the

\footnotetext{
*Correspondence: r.giles@umcutrecht.nl

${ }^{2}$ Department of Nephrology and Hypertension, University Medical Center Utrecht, Heidelberglaan 100, F03.223, 3584 CX, Utrecht, The Netherlands Full list of author information is available at the end of the article
}

plasma membrane, a predominantly actin cytoskeletonmediated process [4], the additional structures allow proper docking at the cell membrane, a complex process that requires the interplay of at least Ofd1, Ofd2, Ninein, Mks1, Mks3, Cep164, Poc5 and Cep123, and is extensively reviewed by Reiter, Blacque and Leroux [5]. Initial invagination and centriolar elongation of the ciliary vesicle occurs prior to membrane docking in most cell systems, but can also occur in later stages. Correct lengthening of the mature centriole is critical, and is ensured by interplay of a network of proteins including CP110, CEP97, KIF24 and TTK2 [6,7]. Once the BB has docked and fused with the plasma membrane, growth of the axoneme can be initiated, a process fueled by targeting additional vesicles to the BB. Interestingly, the efficacy of this growth is highly dependent on the dynamics of local actin filaments [8].

Polarized vesicle transport to the $\mathrm{BB}$ is an extremely complex process and only a few of the proteins/events required have yet been identified. Firstly, microtubules must extend from microtubule organizing center and link the golgi-ER to the basal body, the microtubule- stabilizing and

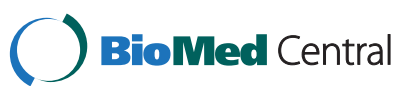




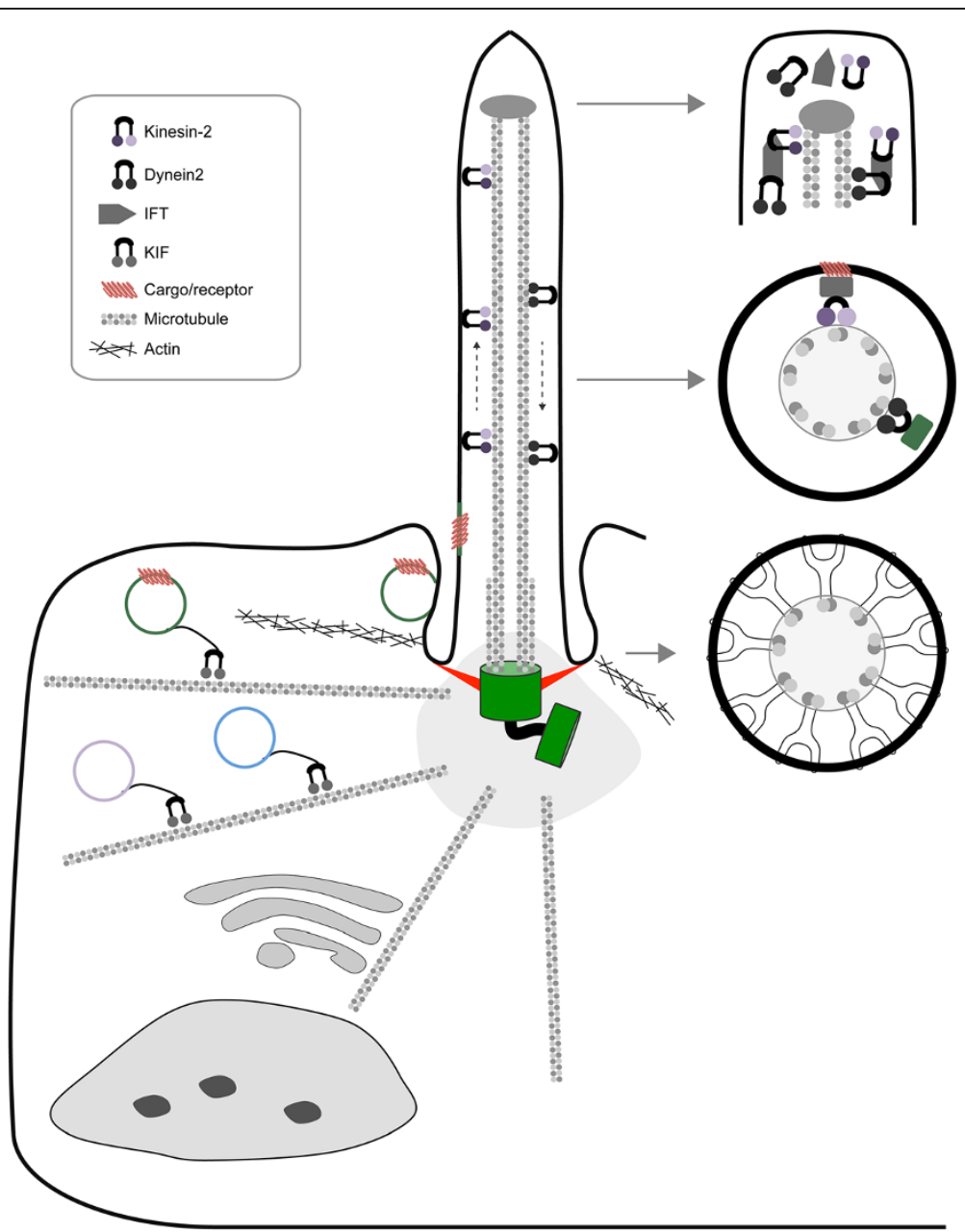

Figure 1 Structure of the primary cilium. The two centrioles are surrounded by the pericentrosomal matrix, serving as basal body and microtubule organizing center. Vesicular transport delivers ciliary components either to the basal body or ciliary pocket. Axonemal import is regulated by the transition zone, which is marked by Y-links. Anterograde kinesin-2- and retrograde dynein-2-mediated IFT sustain ciliary maintenance and cilia-dependent signaling; the complex rearranges at the ciliary tip.

nucleating proteins EB1 and EB3 are required for microtubule minus-end anchoring, defects in which result in defective cilia biogenesis [9]. BB-targeted vesicles are covered with coat-proteins for specificity including members of the TRAPII, clathrin and exocyst systems (reviewed by Hsiao, Tuz and Ferland) [10]. Perhaps the best-studied example of vesicle transport is the BBSome; a protein complex that forms a cilia-specific transport module [11]. An additional regulatory layer is mediated by Ras-superfamily GTPases of Rab and Arl/Raf subtypes. These molecular switches can undergo conformational change upon binding or hydrolyzing GTP, a process regulated by guanine exchange factors (GEF) and guanine activating proteins (GAP). For example, Rab8, Rab11 and the GEF Rabin8 regulate transport of the BBSome [12]. Alternate ciliaassociated vesicle targeting GTPases are Arl3, Arl6 (BBS3) and Arl13 [10]. Finally, kinesin molecular motors transport the vesicles. Beyond the well-described kinesin- 2 motor complex, little is known about other members of the large and diverse superfamily of kinesins that contribute to ciliogenesis. Importantly, cilia are highly dynamic structures requiring a continuous supply of molecules for their maintenance [13]. Vesicles can alternatively dock to the ciliary pocket, a highly specialized endocytic membrane domain characterized by an invagination of the cell membrane peripheral to the axoneme [14]. The ciliary pocket is thought to be a zone of excessive crosstalk between the ciliary membrane and plasma membrane characterized by the presence of many endocytosis-associated clathrincoated pits [15]. Finally, vesicles could potentially dock to the ciliary rootlet; a basal body-associated structure that extends into the cytosol which can at least interact with kinesin light chain subunits [16].

The transition zone (TZ) is just distal of the mother centriole and forms a barrier to regulate protein entry into the cilium [17]. Structurally, the TZ is composed of 
transition fibers, the ciliary necklace and Y-fibers essential for membrane anchoring and formation of a selectively permeable pore (reviewed by Garcia-Gonzales and Rieter [17]). Size-exclusion prevents large structures from entering the axoneme [18]. In addition, components of IFT complexes have been reported to dock to these fibers and possibly participate in regulation of ciliary entry [19]. The Y-links are composed of protein networks, many members of which are encoded for by classic ciliopathy disease loci (described below). Located adjacent to the axonemal microtubules is a core protein complex consisting of NPHP1, NPHP4 and NPHP8 [20], which interacts with a second core complex termed the MKS-JBTS module [21]. The MKS-JBTS module contains distinct proteins, many of which have lipid-binding domains ( $\mathrm{C} 2$, B9 domains) including MKS1, B9D1 and B9D2; these proteins interact with the ciliary membrane [17]. Anchoring to the membrane requires transmembrane domain-containing proteins (TMEM), such as TMEM216 [22] and TMEM237 [23] and interacting proteins TMEM67 [24], TMEM231 [25] and putatively TMEM107 [26]. Moreover, SEPT2 forms a diffusion barrier at the base of the cilium [27]. An emerging aspect of regulated cilia entry is a proposed import system that is analogous to and overlaps with the nuclear pore complex. This so-called ciliary pore complex contains well-known members of the nuclear pore complex, including RanGTPases, importins and nucleoporins which are known to localize to the ciliary base [18]. In line with this notion, some proteins contain ciliary localization sequences, including PC1 [28], fibrocystin [29], KIF17 [30], gpr161 [31] and some myristoylated proteins such as NPHP3 [32].

Nine highly stable axonemal microtubule doublets serve as major transport fibers for intraflagellar transport (IFT), an exclusively ciliary transport mechanism that was identified by pioneering studies of the Rosenbaum lab [33]. Kinesin-2, composed of KIF3A, KAP3 and KIF3B or KIF3C [34], transports selected cargo and dynein-2 during anterograde IFT transport towards the ciliary tip. The complex rearranges at the tip where dynein-2 becomes activated, facilitating retrograde IFT transport [13]. Both kinesin-2 and dynein-2 transport a large protein complex that contains two biochemically and functionally distinct core sub-complexes termed IFT-A and IFT-B. The IFT-B complex is composed of 14 members, including the hallmark IFT88 protein [13]. Dysfunctional IFT-B proteins typically disturb axonemal growth, indicating that this complex mainly functions in anterograde transport. In contrast, the six IFT-A members seem to be mainly involved in retrograde transport; accordingly, defects in IFT144 as well as dynein-2 lead to accumulation of IFT particles at the ciliary tip, generating a bulge [35]. It should be stressed that this view is a simplification of the reality; certain members of both complexes are known to cause inconsistent phenotypes. The core IFT-A, IFT-B, and either kinesin- 2 or dynein-2 complexes are thought to facilitate import across the transition zone as well as distribution of cargo-proteins along the axoneme [13]. Currently, we are only beginning to understand the full complexity of achieving specific ciliary import and distribution. Moreover, it is not entirely clear which IFT components are essential or dispensable for cilia formation. Finally, once the primary cilium is matured, constant maintenance is required to render cilia functional. As protein synthesis is absent in the axoneme, ciliary components need to be constantly imported and exported, a function which is highly dependent, but not exclusively restricted to the kinesin-2/IFT system [33]. A number of alternative kinesins appear to have an accessory role in cilia function. This includes KIF17, the ortholog of Caenorhabditis elegans OSM-3, a co-factor in axonemal transport required for distal end formation in a subset of sensory cilia [34]. While vertebrate KIF17 appears mostly required for targeting specific ciliary components and for photoreceptor outer segment function, some results are contradictory [36,37]. Another kinesin implicated in cilia function, but not essential for cilia structure or morphology, is the Caenorhabditis elegans gene $k l p-6$, encoding a kinesin-3 member that transports mechanosensory polycystins in cilia [38]; however, a mammalian ortholog has not yet been described. Finally, KIF7 is the mammalian ortholog of Drosophila Costal2, and an important mediator of sonic hedgehog-signaling in mammals [39]. Although its ciliary transport is pivotal for hedgehogsignaling, it is neither required for cilia formation nor stability [39].

\section{Specialized cilia function}

Generally speaking, cilia transduce signals from extracellular stimuli to a cellular response that regulates proliferation, differentiation, transcription, migration, polarity and tissue morphology [40]. The textbook example is the renal primary cilium; a non-motile sensory monocilium extending from the epithelial apical membrane into the fluid-filled lumen, easily accessible to extracellular modulators such as mechanical forces and freely diffusing biological agents. Similar primary cilia can be found on other epithelia in organs containing tubular or acinar structures such as the pancreas [41], and cells of the central nervous system (CNS) [42]. Cilia expressed in endothelial cells of the cardiovascular system protrude far less into the lumen and are implicated in sensing fluid dynamics [43]. Endothelial cilia appear more submerged in the cell and are characterized by the presence of deep ciliary pockets [15], cumulus cells in developing oocyte structures also exhibit similarly deep ciliary pockets [14]. More specialized types of cilia, such as the retinal-connecting cilium and kinocilia together with actin-based stereocilia, can be found in the visual and auditory systems. An intriguing recent addition to the 
growing spectrum of ciliary subtypes is the immunological synapse formed by T-cells towards antigen-presenting cells which is highly dependent on IFT proteins and therefore considered a functional homolog of the primary cilium [44]. Although most cilia subtypes function through outside-in sensation, some cilia are able to manipulate the extracellular environment, for example, at the node where their swirling motion induces fluid flow that subsequently asymmetrically deposits morphogens to establish body-axis polarity [45]. Here, cilia motion is achieved through the orchestrated regulation of dynein arm complexes [45]. The regulation of body-axis polarity is however more complex and incompletely understood, and depends on the interplay of centrally placed motile cilia and peripheral mechanosensory primary cilia that asymmetrically display an elevated $\mathrm{Ca}^{2+}$ response and corresponding changes in downstream gene expression [45].

Sperm motility is similarly achieved through swirling motion, but these cilia (or flagella) can also display a whip-like beating pattern, attributable to an additional central pair of microtubules. Finally, beating cilia can also be found in ependymal cells, fallopian tube epithelia and epididymis epithelia, generating fluid flow, or, in the trachea, stimulating mucus transport [1]. Despite this large diversity, when pan-ciliary processes are disturbed, multiorgan pathologies arise that are collectively termed 'ciliopathies' [46].

\section{Ciliopathies}

In their landmark paper, Pazour and colleagues [47] describe the IFT core component Ift 88 to be essential in Chlamydomonas reinhardtii and mouse primary cilia formation, thereby kicking off more than a decade of research that has highlighted the importance of cilia function in development and tissue homeostasis. Given the broad expression and function attributed to cilia [48] it is not surprising that defects in this organelle gives rise to a multitude of organ-specific functional defects and pathologies, most of which are prominent in a number of pleiotropic disease-syndromes.

There are many phenotypes that regularly associate with ciliopathies. Common ciliopathy disease syndromes are Bardet-Biedl syndrome (BBS), Jeune asphyxiating thoracic syndrome (JATD), orofaciodigital syndromes (OFD), nephronophthisis (NPHP), Meckel syndrome (MKS), Senior-Løken syndrome (SNLS), Sensenbrenner, Joubert syndrome (JBTS) Alström syndrome (ALSM), Usher syndrome (USH), Leber congenital amaurosis (LCA), shortrib polydactyly syndromes (SRPS) and Ellis van Creveld syndrome (EVC) [46,49]. Most notably affected is the kidney, which features the development of renal cystic expansion that is comparable to lesions caused by autosomal dominant and recessive forms of polycystic kidney disease (ADPKD, ARPKD) [50], coupled with degeneration and increased fibrosis in the case of nephronophthisis [49]. Cyst formation can also often be observed in the pancreas and liver [51]. Other frequently observed disease manifestations are retinal and auditory defects such as retinitis pigmentosa (RP), retinal dystrophy and sensorineural hearing loss [46]. Severe ciliopathies are characterized by abnormal bone development that can be apparent as short ribs and shortening of the long bones, polydactyly and severe craniofacial malformations [52]. Somewhat overlapping with the craniofacial phenotypes are CNS defects, including encephalocoele, hydrocephalus and cerebellar abnormalities such as corpus callosum aging and cerebellar vermis hypoplasia $[46,53]$. The capacity of the brain to interpret the senses is often affected in ciliopathies, resulting in neurological disorders; cognitive impairment, anosmia, mental retardation, autism, and obesity are apparent in various degrees in many of the ciliopathies [53]. In line with this hypothesis is the recent study testing genes implicated in the neuropsychiatric disorders schizophrenia, bipolar affective disorder, autism spectrum disorder and intellectual disability; the authors identified 20/41 genes to reduce and $3 / 41$ to increase cilia length [54].

A unique category of ciliopathies is associated with motile cilia dysfunction in primary ciliary dyskinesia (PCD) or Kartagener's syndrome. Here, primary cilia function without apparent defects, but motile cilia are affected. Failure to generate ciliary motion can cause situs inversus (only associated with Kartagener's syndrome), infertility due to immotile spermatozoa and recurrent airway diseases resulting from suboptimal mucus clearance from the trachea and lungs and subsequent extended exposure to pathogens. Clinical symptoms include chronic otitis media, rhinitis, nasal congestion, sinusitis and bronchiectasis [55].

Large-scale genetic, proteomic, and genotype-phenotype studies have generated an ever-growing list of crucial ciliary mediators. Roughly 1,000 proteins comprise the ciliome, calculated from a combination of proteomics and comparative genomics [56]. There is significant pleiotropy in the various ciliopathy syndromes, as well as a gradual increase in severity of disease, indicating that some cilia processes are only slightly modified, whereas others severely impaired. To date, mutations have been recovered at $>50$ ciliopathy disease loci, but novel loci are recovered at a high rate. For extensive reviews on the clinical pathologies and genetics associated with ciliopathies we recommend excellent recent reviews by Tobin and Beales [46], Waters and Beales [49], D’Angelo and Franca [51] and Davis and Katsanis [57].

\section{Ciliary signaling}

The cilium protrudes into the extracellular environment, rendering it susceptible to outside-inside-signaling excited by extracellular cues including flow (kinetic) and 
morphogenic, olfactory and hormonal (chemical) stimuli. The cilium forms a semi-closed system requiring regulated import, retention, and export of components [17] which allows a controlled regulation of signaling molecules passing through the cilium. In recent years, a number of core signaling pathways have been described to depend on intact cilia.

Physical sensation of flow, pressure, touch and vibration is referred to as mechanosensation. Although cilia are flexible, there is a basal level of rigidity provided by the axonemal microtubule network. Much of our understanding of mechanosensory mechanisms associated with cilia were derived from studies of renal tubules that are lined with ciliated epithelial cells, where the force of luminal fluid flow determines the direction and bending of the cilium (Figure 2A) [58]. The polycystin proteins PC1 and PC2 (encoded for by PKD1 and PKD2 genes which when mutated cause ADPKD) play a key role in mechanosensation and heterodimerize into an ion channel-complex [58].
The causal gene for the related pathology ARPKD, the PKHD1 gene encoding fibrocystin, is associated with the polycystin complex [59]. Upon shear stress, the polycystin complex opens and imports extracellular $\mathrm{Ca}^{2+}$, elevating the intracellular $\mathrm{Ca}^{2+}$ concentration. Subsequently, modulated intracellular $\mathrm{Ca}^{2+}$ levels can act as a general second messenger to affect multiple downstream processes. Next to its role in mechanosensation, PC1 can additionally act as a transcriptional activator. In the presence of flow, PC1 is normally sequestered to the cilium; when flow is ceased, protealytically cleaved PC1 can, together with STAT6 and p100, activate a transcriptional program [60]. The relevance of polycystin function in adult tissue appears overall less dramatic compared to developmental stages, showing rather mild renal failure compared to the acute development of large cysts respectively [61].

The complexity of $\mathrm{Ca}^{2+}$ as a second messenger is complicated by excessive cross-talk between down-

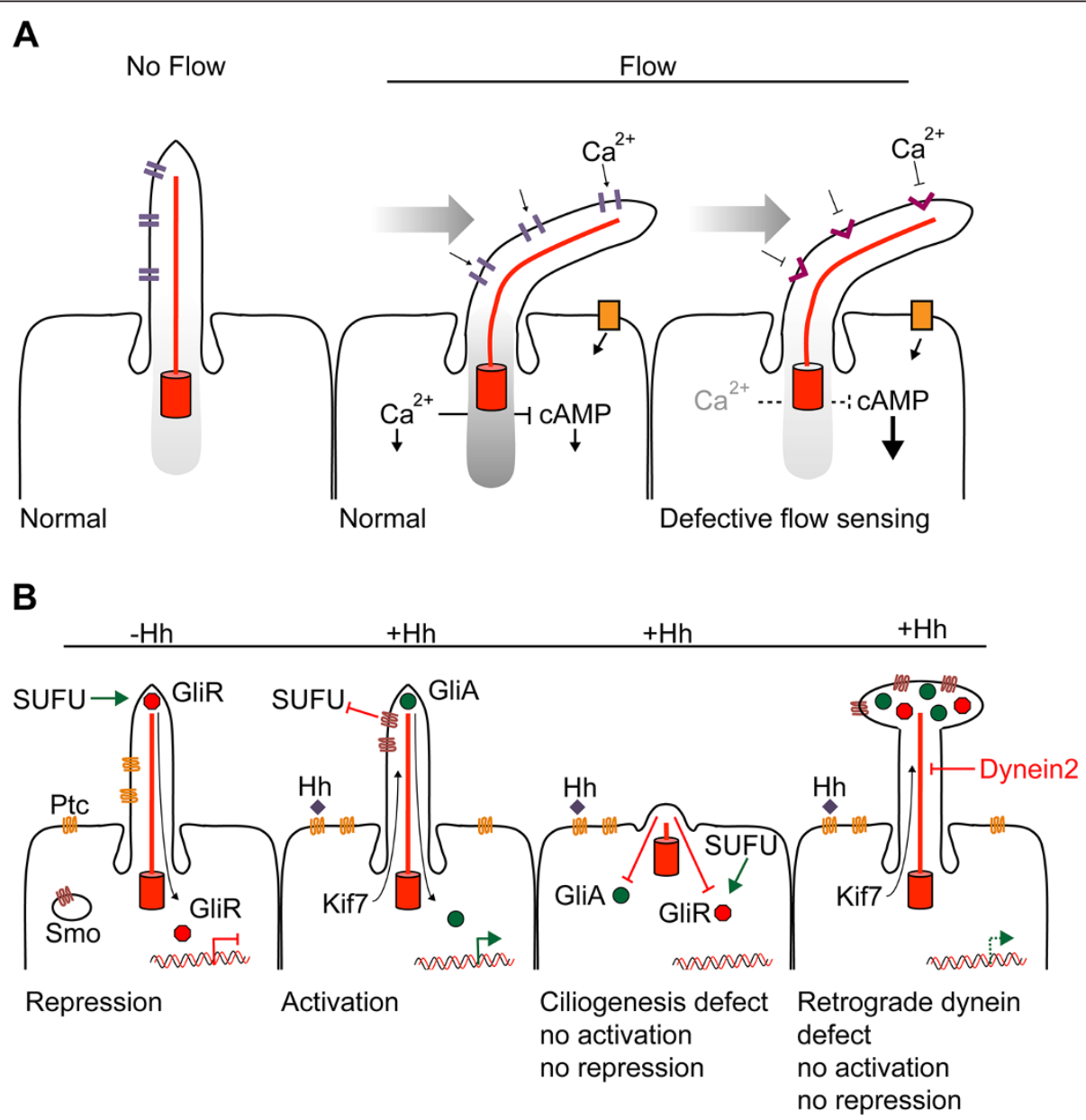

Figure 2 Ciliary signaling. (A) Mechanosensation. Flow induces cilia bending, the polycystin complex is a Ca ${ }^{2+}$ channel and causes an increase of intracellular $\mathrm{Ca}^{2+}$ levels that acts as a second messenger. In PKD, the polycystin complex fails to elevate intracellular $\mathrm{Ca}^{2+}$ hence mechanosensation is perturbed, leading to inappropriate responses and eventually cyst formation. (B) Schematic representation of Hh-signaling in normal conditions with and without Hh-ligand present. Abnormal Hh-signaling in the absence of primary cilia or in retrograde dynein-2 mutants. 
stream targets and the large number of potentially affected targets. One important pathway downstream of mechanosensation-induced $\mathrm{Ca}^{2+}$-signaling is the Wntpathway. In unperturbed renal epithelial cells, for example, increased $\mathrm{Ca}^{2+}$ promotes the non-canonical over canonical signaling, whereas in various ciliadefective cells, an upregulation of canonical Wntsignaling is noted [62]. The Wnt-signaling pathway is discussed in more detail below.

In other cell types, including sensory neurons, cilia bending also results in modified cAMP- signaling which can ultimately activate MAP/ERK-signaling and downstream proliferation [63]. In PKD, reduced intracellular $\mathrm{Ca}^{2+}$ concentration results in decreased phosphodiesterase 1-mediated conversion of cAMP to AMP, with consequent amplification of cAMP-signaling and downstream MAP/ ERK target activation [62]. In turn, deregulation of the TSC1/2-mTOR pathway by cAMP/MAPK also associates with PKD; however the direct role of $\mathrm{Ca}^{2+}$ in mTORsignaling has not been properly studied. For detailed reviews on cilia/ $\mathrm{Ca}^{2+}$ - signaling in the developments of renal cysts, we refer to comprehensive reviews by AbdulMajeed and Nauli [62] and Kotsis, Boehlke and Kuehn [64]. Other regulators of mechanosensation, physical conditions such as osmotic pressure, heat shock, touch and extracellular matrix movements or vibrations can also excite ciliary-signaling and the mechanisms involved are slowly emerging $[65,66]$.

Hedgehog (Hh)-signaling largely depends on cilia integrity. It was noted that inhibition of ciliogenesis in mouse knockout models of kif3a or ift 88 showed phenotypic overlap with mutant members of the hedgehog-signaling pathway [1]. Hh-signaling is implicated in many diverse (embryonic) developmental processes and includes regulation of tissue patterning and cellular differentiation, proliferation and survival [67]. Hh-signaling can be initiated by three ligands; sonic-Hh (Shh), Indian-Hh (Ihh) and Desert-Hh [68], the summarized mechanism described below is based on the best characterized member Shh. Although the exact mechanisms are not fully elucidated and there appears to be tissue-specificity, there is a basic understanding of how the pathway acts through the cilium (Figure 2B). In the absence of Hh-ligand, the hedgehog ligand binding receptor Patched (Ptc) localizes to the cilium and through an unknown mechanism Smoothened (Smo) is mostly retained in vesicles and excluded from localizing to the plasma membrane and entering the cilium [69], although a basal level is thought to traffic through cilia as well [70]. There are three mammalian paralogs of the Glioma family described; Gli1, a transcriptional activator that is upregulated after initial pathway activation, Gli2, the principal transcriptional activator and Gli3, the principal transcriptional repressor [71]. In the absence of Hh-ligand, Gli2 and Gli3 are complexed with the negative regulator Sufu and Kif7, which serves as a scaffold for PKA, GSK3 $\beta$ and CK1, promoting a cullin3/ ubiquitin proteasomal-mediated cleavage that generates the Gli2R and Gli3R repressor forms, allowing the GliR's to translocate to the nucleus and repress transcription [72]. In the presence of Hh-ligand, Ptc is excluded from the cilium and Smo becomes activated and translocates to the ciliary membrane, facilitated by $\beta$-arrestin and Kif3a and possibly other factors [71]. Simultaneously, Kif7, Sufu, Gli2 and Gli3 transition to the ciliary tip and the Sufu interaction is lost, allowing Gli2A and Gli3A stabilization. How Smo exactly activates GliA is not fully elucidated, but ciliary Smo is required for GliA formation, and probably does so by antagonizing Sufu. Although GliR regulation by Sufu does not require the presence of cilia [73], efficient formation of the repressor forms does not occur in cells without cilia [74]. Upon activation, GliA is dependent on retrograde IFT (dynein mediated) to exit the cilium after which it translocates to the nucleus to drive the expression of target genes. Defects in cilia integrity therefore modulate Hh-signaling, and depending on the underlying defect, either activate or dampen Hhsignaling [69]. Developmental processes that depend on hedgehog activity, such as neural tube patterning, are affected by defects in the pathway activation as is observed in cilia-deficient cells that fail to generate GliA. Alternatively, limb development requires efficient GliR formation, which is also perturbed in cilia-deficient cells [69]. Kif3a mutants, most IFT-B complex mutant alleles that perturb cilia formation (IFT52, 57, 88, 172), as well as other inhibitors of cilia formation such as TTK2, result in a constitutive dampening of the Shh pathway, as cilia are required for proper GliA and GliR processing [7,75,76]. Defects in the dynein- 2 motor impede retrograde transport leading to an accumulation of proteins at the ciliary tip; consequently the membrane at the ciliary tip expands to form a bulge [77]. Dynein-2 mutations also impair Hh-activation due to the inability of GliA to translocate to the nucleus. Mutations affecting IFT-A complex members IFT139/ TTC21B and IFT122, which primarily regulate retrograde axonemal transport, hyperactivate the pathway [78,79]. In contrast, other IFT-A mutants (IFT121, IFT144) display similar effects to IFT-B mutants, indicating that these are required for cilia formation, possibly reflecting the complexity of interplay between IFT-A members in transport of membrane proteins like Smo and ACIII [35]. For an extensive description of the relation between cilia and Hhsignaling, we recommend reviews by Goetz and Anderson [69] and Robbins et al. [71].

Both canonical and non-canonical Wnt-signaling regulate developmental and homeostatic processes [80]. The cilium seems to play a role in dictating the outcome of Wnt-ligand binding towards either pathway, but the details are not fully understood and data occasionally 
conflict. Put simplistically, in the absence of canonical Wnt-signaling, $\beta$-catenin is caught in a destruction complex together with Axin, adenomatous polyposis coli (APC), casein kinase 1 (CK1) and glycogen synthase kinase $3 \beta$ (GSK3 $\beta)$ [80]. Wnt-ligand binding to the transmembrane receptors frizzled $(\mathrm{Fz})$ and low density lipoprotein receptor-related protein 5/6 (LRP5/6), recruits dishevelled (Dvl) and Axin, resulting in disassembly of the destruction complex and subsequent accumulation of $\beta$-catenin in the nucleus, where it regulates transcription factors [80]. One body of evidence suggests a role for cilia in restraining canonical Wnt (Figure 3A). Downregulation of essential ciliogenesis genes BBS1, BBS4, MKKS or KIF3A in HEK293T cells and zebrafish embryos [81] as well as Kif3a, Ift88, Ofd1 in murine cells [82] lead to nuclear $\beta$-catenin accumulation and enhanced transcriptional activity of canonical Wnt target genes. Similarly, genetic mutant Chibby mice [83] as well as zebrafish mutant for the seahorse allele [84], encoding cilia-associated (Chibby) and related (Seahorse) proteins, result in canonical Wnt activation. The nephronophthisis protein NPHP2/INVS normally recruits Dvl, thereby rendering $\beta$-catenin in the destruction complex; disruption of INVS allows Dvl to translocate to the membrane potentiating nuclear $\beta$-catenin accumulation [85,86]. Furthermore, nuclear $\beta$-catenin is a common hallmark of renal cysts, and oncogenic $\beta$-catenin is sufficient to drive cytogenesis [87]. The JBTS protein Jouberin/AHI1 also seems to inhibit canonical $\beta$-catenin-signaling via sequestration to the primary cilium; AHI1 regulates both $\beta$-catenin nuclear import and ciliary localization. Defects in cilia formation potentiate Wnt responsiveness, and tethering $\beta$-catenin to the cilium reduces canonical Wnt-signaling [88]. In line with this notion, Ahi mutant mice do not show nuclear $\beta$-catenin accumulation and signaling in their kidney cysts, which also raises the question of how relevant canonical Wnt-signaling is for renal cyst development [89]. Several other studies similarly contradict the activation of Wnt-signaling solely due to cilia disruption; Ift88, Ift172 and Kif3a mutant mouse embryos and maternalzygotic zebrafish ift88 mutants do not show altered canonical Wnt-signaling $[90,91]$, suggesting that results reflect tissue and developmental stage-specific discrepancies [69]. Another study indicated that altered Wnt-

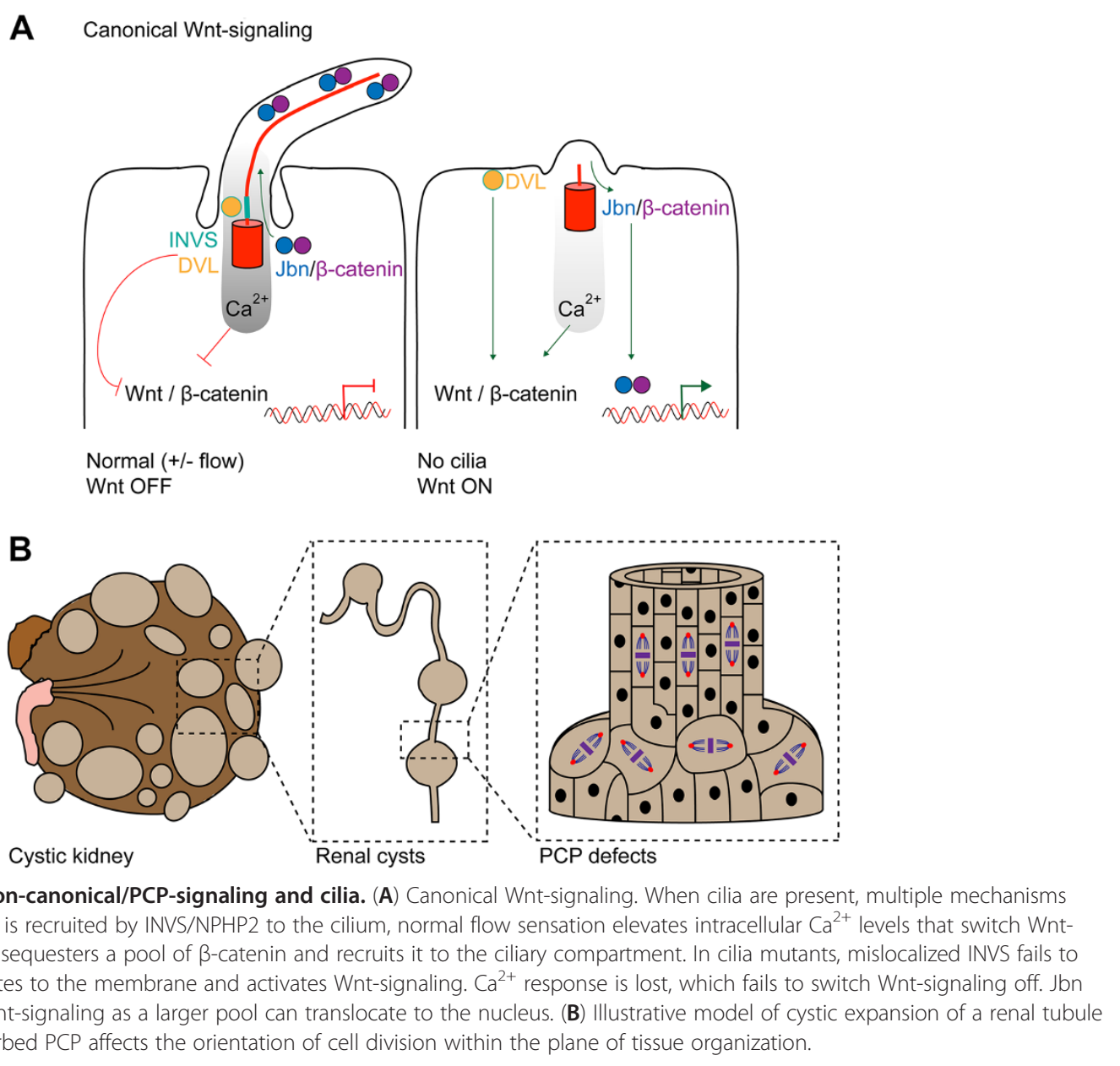

Figure 3 Canonical and non-canonical/PCP-signaling and cilia. (A) Canonical Wnt-signaling. When cilia are present, multiple mechanisms dampen Wnt-signaling; DVL is recruited by INVS/NPHP2 to the cilium, normal flow sensation elevates intracellular Ca ${ }^{2+}$ levels that switch Wntsignaling off, Jouberin (Jbn) sequesters a pool of $\beta$-catenin and recruits it to the ciliary compartment. In cilia mutants, mislocalized INVS fails to recruit DVL, which translocates to the membrane and activates Wnt-signaling. Ca ${ }^{2+}$ response is lost, which fails to switch Wnt-signaling off. Jbn and $\beta$-catenin potentiate Wnt-signaling as a larger pool can translocate to the nucleus. (B) Illustrative model of cystic expansion of a renal tubule in a polycystic kidney. Disturbed PCP affects the orientation of cell division within the plane of tissue organization. 
signaling is a secondary defect of modified Hh activity [92]. Importantly, $\mathrm{Ca}^{2+}$ levels can also affect the canonical Wnt pathway [93], and $\mathrm{Ca}^{2+}$ influx as a result of mechanosensation is proposed to switch canonical Wnt off, whilst turning non-canonical signaling on [94]. The absence of proper flow-sensing in organs with dysfunctional cilia impairs $\mathrm{Ca}^{2+}$-mediated Wnt regulation which further complicates dissection of the various pathogenic pathways. Likely Wnt regulation occurs through various mechanisms, even in close proximity to the cilium and basal body and the effect of cilia towards canonical Wntsignaling is subtle, dependent on cell type and developmental stage. Generally, defects associated with defective cilia/ $\beta$-catenin-signaling appear less severe compared to Hh- mediated-signaling [95].

In the non-canonical pathway, $\beta$-catenin is dispensable and Wnt-signals act under control of planar cell polarity (PCP), but again there are conflicting data on the direct role of cilia in PCP-signaling. PCP regulates the correct expansion and homeostasis of polarized tissue (Figure 3B) and it is evident that many ciliopathies feature PCP defects; for example, the cystic phenotypes are likely a defect of altered PCP [50]. Convergent extension during gastrulation in development is a PCP-mediated process, and defects in cilia genes such as INVS, BBS1, BBS4, $B B S 8, M K K S$ and OFD1 induce convergent extension defects [95]. These data collectively point to the hypothesis that cilia are involved in the switch between canonical and non-canonical Wnt-signaling, which is independent of the PCP-signaling pathway [95]. A developing view in the field is that cilia are not extensively involved in regulation of polarity proteins through deregulating PCPsignaling, but that this defective polarity is the result of mis-positioning of the centrosome during cell division [95]. Indeed, many ciliopathy proteins such as IFT88, OFD1 and BBS4 are essential for proper centrosome composition and structural stabilization [96-98]. PCPsignaling itself can affect correct basal body docking and ciliogenesis [99]. Studies in mammalian cells are sparse however, and most knowledge has been obtained from Drosophila and Xenopus studies. Essential PCP-signaling molecules that affect ciliogenesis include Fuzzy, Inturned, Fritz and Dvl. The molecular role for these proteins is emerging and it is suggested they affect processes including actin remodeling and ciliary-vesicle transport [95]. For a more extensive discussion about the relation between cilia, Wnt-signaling and PCP we recommend a review by Wallingford [95].

Platelet-derived growth factor (PDGF)-signaling affects cell migration, proliferation and survival [100]. Upon cell cycle exit, the receptor PDGFR $\alpha$ is upregulated and localizes to primary cilia in cultured fibroblasts [101]. Binding of the ligand PDGF-AA activates the dimerized PDGFR $\alpha \alpha$ receptor and downstream Akt, ERK1/2- and
MEK1/2-signaling molecules [101]. Defects in primary cilia formation disrupts PDGF-AA-signaling and affects endothelial cell function [102]. The PDGF receptor is a receptor tyrosine kinase (RTK); recently other RTKsignaling events were described as being mediated through primary cilia in some cell culture models, including epidermal growth factor receptor (EGFR), insulin-like growth factor (IGF1R), and the angiopoietin receptor (Tie-2), For a detailed description of the implications RTK-signaling might have in light of cilia sensing, we refer to a recent review by Christensen, Clement, Satir and Pedersen [103]. Fibroblast growth factor (FGF)- signaling has been shown to affect cilia length and affect left-right determination, a process dependent on proper cilia functioning [104].

Hippo-signaling (Salvador-Warts-Hippo) has recently been added to the growing list of signaling pathways at least partly regulated through the cilium. Hippo-signaling is based on a number of serine/threonine-kinases that are involved in controlling organ size and cell proliferation. Many members act as tumor suppressor proteins as well as proto-oncogenes [105]. NPHP4 interacts with the Hippo regulator LATS, allowing the transcription factors YAP and TAZ to translocate to the nucleus. In the absence of NPHP4, Hippo-signaling is overactive and cell proliferation is limited. NPHP4 may regulate the renal fibrosis associated with most ciliopathies through CTGF transcriptional regulation [106]. The Crumbs receptor family is known to affect Hippo-signaling [107] and Crumb3 has been shown to localize to the cilium [108]. Furthermore, Hippo pathway core component Mob1 delays ciliogenesis in Tetrahymena [109]. Histological examination of human PKD sections demonstrates nuclear translocation of YAP and TAZ [110], and deregulated Hippo-signaling itself can result in cyst formation, possibly through crosstalk between Hippo- and canonical and non-canonical Wnt-signaling [94].

Apart from these core-signaling pathways receiving much attention in the past years, new developments have expanded the list of cilia-related-signaling. In endothelial cells, endothelial to mesenchymal differentiation depends on cilia function towards TGF $\beta$ activity [111]. In skin development, cilia are required for proper Notch-signaling and progenitor cell differentiation [112]. Tubby proteins were recently shown to serve a bridging function between specific membrane domains and IFT, affecting signaling [113], and alterations of cilia membrane composition itself are sufficient to disrupt signaling [114,115]. The coming years will likely show an upsurge of signaling modulation regulated by the primary cilium.

\section{Reciprocal regulation of cilia and the cell cycle}

The eukaryotic cell cycle dictates and regulates cellular duplication, and recognizes five consecutive but distinct 
phases. The basal stage is referred to as interphase or G1. The G1 centrosome has one mature or mother centriole that is equipped with distal appendages and one incomplete daughter centriole. Once cells are properly stimulated by mitogenic or growth factors they prepare for entry into S-phase, and towards the end of G1-phase the daughter centriole matures to a full-length centriole. When cells enter S-phase, the chromosomes and the centrosome are duplicated and both centrioles serve as a platform to assemble two new incomplete centrioles; master regulators driving centrosome duplication include PLK4 and SAS6 [116]. Following S-phase, cells enter G2 to prepare for the physical chromosome partition; the initial mother and daughter centrioles together with the newly formed pro-centrioles separate and migrate to opposing sides. After nuclear envelope breakdown and chromosome condensation, the centrosomes become a regulatory center for bipolar spindle formation that connects microtubules to the chromosomes. During metaphase, all chromosome pairs must be connected to either centrosome and congress to the metaphase plate. Once the spindle assembly checkpoint is inactivated cells proceed into anaphase, the duplicated chromosomes are disengaged and exactly one copy of each moves apart towards the centrosome. The site of the metaphase plane now becomes a site where the membrane is progressively invaginated. The remaining microtubules allow membrane vesicles to accumulate and deposit membrane and other essential components of the cytokinetic machinery. When the remaining cleavage furrow is broken, cells pinch off from each other and return to G1. During late G2/M, the daughter centriole has matured to a mother centriole with the addition of distal appendages. After cell division, each cell contains one new centrosome composed of either a grandmother or mother centriole and both contain one incomplete daughter centriole [116]. Most cells in the human body will enter the G0 or quiescent stage after successful cell division (Figure 4). Because the centrosome is involved in both cell division and ciliogenesis, these processes are mutually exclusive and there is a continuous tipping of balance to recruit the centrosome for either process. Upon entrance into G0, the mother centrioles have the unique capacity to dock to the cell membrane and initiate axonemal growth, as discussed above. An exception to the rule are multiciliated cells; in these terminally-differentiated cells, centrosomes must be assembled de novo and one cell can form up to hundreds of centrosomes, each having the capacity to form a cilium [116].

A number of proteins intimately associated with ciliogenesis and cilia function are additionally implicated in cell cycle control, which can be achieved by functioning within any of the numerous essential cell cycle processes described above. We will first discuss the cell cycle defects observed for a number of cilia proteins that can result in alterations in cell cycle timing and the fidelity of centrosome duplication, chromosome segregation and cytokinesis. Microtubule-anchoring to the centrosome requires functional BBS4, which interacts with the microtubule network organizer PCM1. Knockdown of BBS4 in cell culture blocks cell division progression and induces an increase in apoptosis [98]. Bbs4 knockout mice similarly show disorganized microtubules in dendrites, but no severe apoptosis was described, suggesting tissue-specificity of the BBS4/PCM1 interaction and redundancy in vivo [117]. A similar mouse knockout phenotype [118] and defect in cytokinesis has been shown for MKKS/BBS6 upon cell culture knockdown, however in contrast to the BBS4 phenotype, no defects in microtubule organization were observed; the authors suggested that the chaperonin activity of BBS6 might be required for a cytokineticspecific process [119]. IFT88 overexpression in nonciliated cells blocks G1/S transition and depletion induces cell cycle progression [120]. IFT88 interacts with the Rb inhibitor Che-1, suggesting a model in which IFT88 depletion allows $\mathrm{Rb}$ to become active and induce cell cycle progression independent of a microtubule and dynein interaction [120]. The ORPK/Ift88 mouse mutant accordingly displays epithelial cell hyperproliferation in several tissues $[121,122]$, but it remains undetermined if this directly attributable to the IFT88/Che-1 interaction, as ciliary- signaling through Wnt, for example, is also modified. Another IFT-B complex member, IFT27, delays cell cycle progression upon knockdown in Chlamydomonas reinhardtii and affects cytokinesis [123]. Apart from associating with the IFT-B complex, stoichiometric data suggests about half of the IFT27 protein does not interact with this complex. Given that IFT27 is a Rab-like Gprotein, it has been suggested that IFT27 might have a transport function from the centrosome to cleavage furrow during cytokinesis [123]. Interestingly, knockdown of IFT27 also resulted in reduced expression of other IFT members, including IFT46, IFT52, IFT81 and IFT139. Another study showed that the IFT27 and IFT46 are dynamically regulated during the Chlamydomonas cell cycle, peaking during the S-M cell division phases, indicating that transcriptional control of these IFT members is restricted within the cell cycle [124]. Furthermore, IFT27, IFT46, IFT72, IFT139 relocalize to the cleavage furrow during cytokinesis [124]. Together with the notion that IFT proteins play roles in non-flagellar transport, such as during the formation of the immunological synapse in $\mathrm{T}$ cells [44], it could now be suggested that some IFT components play general roles in membrane transport, not limited to IFT [124]. This is further supported by the evolutionary origins of core IFT members that share homology to other transport coat complexes such as COPI [125]. This notion is supported by another study 


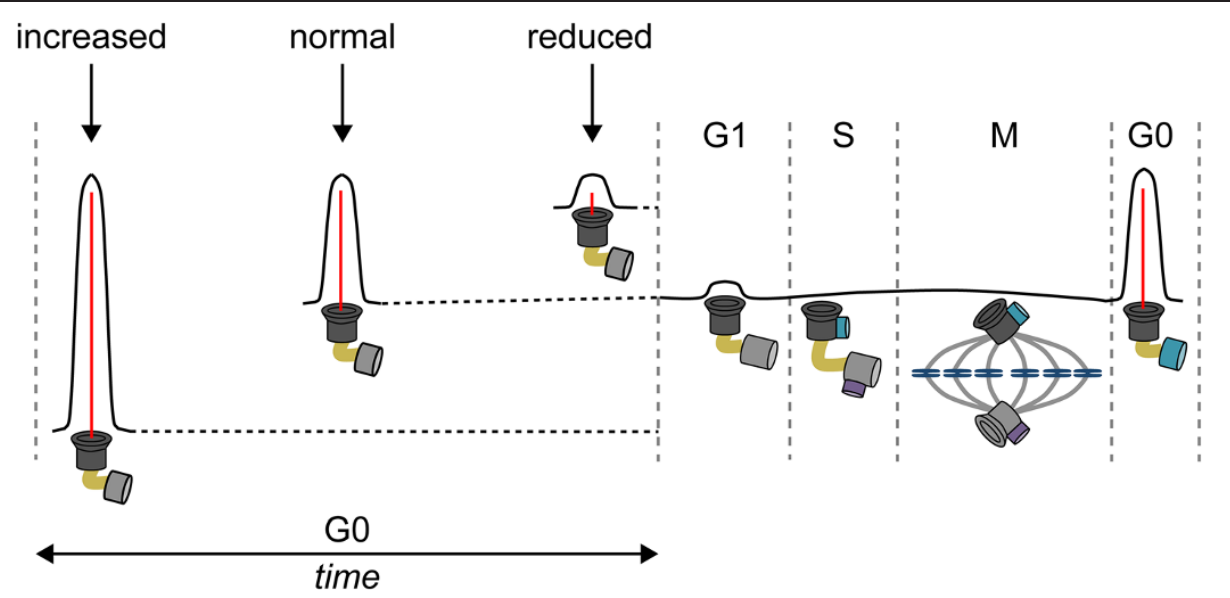

Figure 4 Cilia length in control of cell cycle progression. Cilia provide a physical block for cell cycle progression by laying claim to the basal body. Disassembly of the primary cilium is required to liberate the centrosome and allow duplication during S-phase and subsequent formation of the mitotic spindle during chromosomal segregation. Cilia mutants that inhibit ciliogenesis are prone to initiate rapid cell duplication when properly stimulated, and in contrast, increased axonemal length delays cell cycle progression. The maturation steps (growth and appendages) of the centrioles are indicated during the various cell cycle stages.

that described a large overlap in the cellular machinery to regulate cytokinesis and ciliation by comparative proteomics and was more extensively shown for PRC1, MKLP-1, INCENP and centriolin in Caenorhabditis elegans and cell culture studies [126].

One proposed explanation for the cell cycle defects observed is that the balance between centrosome and basal body transition is disturbed, leading to cell cycle checkpoint activation [127]. This seems to be accompanied by activation of key regulators of the G1/S transition, Cdk2 and cyclin E, when centrosomes are disengaged from ciliation [127]. Alternatively, proteins that are required for centrosome biogenesis and whose absence leads to structural defects, induce a p38/p53/p21-dependent checkpoint activation [128]. Overall, evidence is accumulating that a number of components initially linked to the cilium have functions that are not limited to the cilium alone, but have retained or acquired properties that render them essential to alternative cellular processes. These could either be through evolutionary conservation and a specificity that is less stringent towards the cilium than expected or dual functions of a particular protein.

The mechanisms controlling ciliogenesis are discussed in more detail above, but one of the first prerequisite is the absence of proliferative stimuli; in vitro, most cell lines require serum deprivation to enter G0 and initiate ciliogenesis. Another factor is ascertaining established polarity. Inversely, there are also mechanisms controlling ciliary disassembly, which are incompletely understood. Depending on the cell type, disassembly occurs in S-phase or before the G2/M transition [129], and is known to be initiated in two waves [130]. The best-studied disassembly mechanism involves the Aurora A kinase, which can be activated by the scaffolding protein HEF1/NEDD9. Aurora
A in turn activates the tubulin deacetylase HDAC6, hence destabilizing axonemal microtubules and initiating cilia resorption [130]. Pitchfork/PIFO localizes to vesicles and the basal body and it can similarly activate Aurora A through direct interaction. Reducing PIFO in murine embryos generates mitotically arrested cells with ciliated spindles, whereas overexpression generates centrosomal overduplication [131]. Alternatively, HEF1 can be activated by canonical Wnt-signaling components Wnt3a, Dvl2 and $\beta$-catenin [132]. In addition, activation of the non-canonical Wnt pathway through Wnt5a and casein kinase-1-epsilon-induced complex formation of Dvl2 and Plk1, that stabilizes HEF1 and allows Aurora A activation to induce cilia disassembly [133]. The never in mitosis A (NimA) related kinase NEK2 is another important mediator essential for cilia resorption at the G2/M transition, but the exact mechanisms involved and a connection to the Aurora A pathway are uncertain [134]. In contrast to controlling timely resorption of cilia, other networks of centriolar proteins prevent aberrant cilia assembly. CP110 localizes to the distal end of centrioles where it interacts with, and prevents, NPHP6 and Rab8a from initiating ciliogenesis [135]. A distinct complex of CP110 and CEP97 also prevents cilia assembly [136]. In quiescent cells, both KIF24 and its interaction partners CP110 and CEP97 are removed from the mother centriole distal end to promote ciliogenesis [6]. KIF24 depolymerizes centriolar microtubules to prevent premature cilia assembly, and loss of KIF24 promotes ciliogenesis even in cycling cells [6]. The recently described protein TTBK2 promotes the removal of CP110 to allow for cilia formation [7]. Furthermore, a CP110/Centrin/CaM module regulates cytokinesis [137], indicating a broad functional spectrum for CP110. The complex interplay of regulators 
of correct cilia/centriolar size eventually affects the crossroad of basal body and centrosome.

It is becoming clear that the axonemal length directly influences cell cycle time (Figure 4) and reduction of cilia length or cilia depletion allows cells to enter S-phase more rapidly. Mutations in INPP5E (also called JBTS1) disrupt the balance of phosphoinositides which makes cells more prone to re-enter the cell cycle upon growth factor stimulation; functional in vitro studies suggest the cilium can dampen the response to mitogenic cues and prevent premature cell cycle entry $[114,115]$. INPP5E interacting proteins CEP164, ARL13B and PDE6 are required for INPP5E targeting to the cilium with depletion of these factors associating with the severe JBTS and MKS ciliopathy syndromes [138]. Inversely, increased cilia length can delay cell cycle re-entry. Recently, it became evident that Nde1 and Tctex 1 regulation of dynein subunits affects cell cycle progression [139]. Nde1, which is normally expressed at low levels in quiescence, recruits axonemal dynein complex member LC8 and subsequent cilia length suppression. Depletion of Nde1 results in increased ciliary length, thereby delaying cell cycle progression [140]. Tctex1 associates with the cytoplasmic dynein complex, but upon activation relocates to the basal body where it promotes ciliary disassembly and cell cycle progression [141]. Previously identified factors that increase cilia length are male associated germ-cell kinase (MAK) and cell cycle-related kinase (CCRK) [13]. TSC1 and TSC2 similarly increase cilia length in response to energy/nutrient sensing (discussed further below). Intracellular levels of second messengers also influence cilia length; lowering $\mathrm{Ca}^{2+}$ and elevating cAMP levels increases cilia length. Under flow conditions, intracellular $\mathrm{Ca}^{2+}$ levels rise again and cAMP decreases, reducing cilia length [142]. Phosphatase inhibitor-2 (I-2) is necessary for microtubule acetylation and thus stability, and is located on the membrane in proximity to the docked basal body. Inhibition or deletion of I-2 reduces cilia length [143]. Several ciliopathy syndromes are associated with neurological disorders, suggesting that cilia might be involved in the development of these diseases. A recent RNA interference screen in NIH3T3 cells, targeting selected genes that were previously identified in genome-wide association studies for neurological disorders, indeed appeared to affect cilia length negatively. In contrast, three targets significantly enhanced cilia length; CCDC18, FOXP1 and MIR137, although the underlying mechanism was not determined [54]. Also, G-protein coupled receptors are frequently located to primary cilia, such as serotonin and somatostatin, as well as the recently described shh antagonist Gpr161 [31]. Some G-protein coupled receptors affect cilia length; activation of dopamine D5 receptor increases cilia length [144], as does dopamine receptor D1 [145]. Modification of cilia length might also be important for signal interpretation, for example in the CNS.

\section{Cilia and cancer}

Because cilia have the ability to physically influence the cell cycle and manipulate signaling cascades, it has been a long-running hypothesis that defective cilia biogenesis could be an important step in cancer development. However, much of the data in this arena rests on in vitro studies and it thus remains to be established how, and if, there is a direct relationship between ciliary dysfunction and tumorigenesis. One of the major arguments against a direct role of cilia in tumorigenesis is the lack of evident tumor predisposition in patients with many classic ciliopathies such as SLNS, LCA and NPHP. However, mortality from organ function impairment may mask true tumor incidence in ciliopathy patients. The JBTS disease gene JBN/AHI1 sensitizes tissue for Wnt activation, allowing low Wnt levels to improperly activate cells and induce over-proliferation. Accordingly, oral hamartomas have been associated with Joubert Syndrome-related disorders $[146,147]$. There is some conflicting data on the risk of heterozygote relatives of BBS patients to develop renal cancer; one small study recognized a 17-fold increase risk [148], but a larger study disputed this finding in their cohort [149]. To date though, with the exception of a few case reports, cancer has not been reported to associate systemically with the relatives of these recessive ciliopathies. Heterozygous carriers therefore do not seem to be at increased risk for cancer development, but it will be important to closely monitor these carriers in respect to tumor development and determine putative biallelic inactivation. Impaired cilia function can induce inappropriate responses in progenitor cells, expanding the stem cell compartment or differentiate into dysplastic tissue, as is observed in the epidermis, vascular system and mammary gland $[111,112,150]$. Alternatively, it is becoming evident that many proteins encoded for by familial cancer genes do actually affect cilia function. The cilium is an important mediator of homeostasis and a growing number of proteins which affect both cell ciliation and tumorigenesis have been identified.

\section{Clinical observations of cilia and cancer}

As most tissues in the human body at least have the capacity to express cilia, it is important to address the effect on cilia expression in corresponding tumor types. Currently this is still an understudied field, and only a small number of tumor types have been subjected to detailed cilia analysis [151]. In breast cancer development there is little information on cilia involvement available, however, the cilia-associated genes Gli1 (Hh effector), RPGRIP1 (LCA) and DNAH9 (PCD) are commonly mutated in breast cancer $[152,153]$. A later study indicated that ciliary frequencies are decreased in breast cancer tissue and breast cancer-derived cell lines when compared to normal breast tissue fibroblast and epithelia; cilia 
frequencies after prolonged serum starvation were more severely reduced in cell lines derived from aggressive cancer lines, furthermore this was shown to be independent of increased proliferation through determining the number of Ki67 positive cells [154]. Accordingly, analysis of murine mammary glands indicates that cilia are expressed during development and remain present on myoepithelial and stromal cells but are absent from luminal epithelia in matured mammary glands [155]. Detailed analysis of Hh-signaling and primary cilia in mammary basal cell hyperplasia characterizes the Hhresponsive cells as progenitor-derived cells bearing cilia [150]. The proliferation rates of these cilia-bearing cells is lower compared to control tissue [150]. Furthermore, it was shown that NPHP9 (NEK8), which is upregulated in breast cancer [156], modulates cilia length and activates the oncogenic Hippo pathway transcription factor TAZ [157]. Melanoma development has several stages, ranging from melanoma in situ, primary invasive melanoma and metastatic melanoma. While melanocytes express primary cilia, early melanoma in situ express hardly any cilia, and cilia are completely lost in progressive tumor phases. In this study, proliferation rates as determined by Ki67 staining were typically too low to account for the observed reduction of cilia frequency [158]. Like melanoma, pancreatic ductal adenocarcinoma is also characterized by activated Ras-signaling [158], and similarly reduced ciliary frequencies were observed in early stages of tumor development [41,159]. A loss of cilia was also observed in ovarian cancer originating from the ovarian surface epithelium that were growth arrested to normalize for the effect of proliferation on cilia expression [160]. Another study of an ovarian serous cystadenoma, based on co-evolutionary analyses, identified an overrepresentation of mutated cilia genes in this tissue [161]. On a more general note, co-evolutionary analyses revealed that the cilia proteome (ciliome) evolved concomitantly with multicellularity and adopted important functions in the regulation of cell-division control. Therefore, these authors postulate by extrapolation that deregulation of the ciliary network of proteins will result in proliferation in cancer development [161]. We recently published data suggesting a predisposition for tumor development in zebrafish that carry a heterozygous mutation in cilia gene $\operatorname{lrc} 50$ that also causes PCD [162]. Tumors isolated from these zebrafish are analogous to human seminoma, a subtype of the group of testicular germ cell tumors (TGCT), and germline loss-of-function mutations were identified in human seminomas from patients with a family history of seminoma formation. It is unclear, however, if mutant LRRC50 tumor formation is attributable to impaired cilia function but the mutations found in the seminomas demonstrate cilia-associated gastrulation defects in fish embryos [162]. Colorectal cancer is increasingly associated with a role for cilia. The cilia disassembly promoting kinase Aurora $A$ is often mutated in colorectal cancer [163], as well as Hh member Gli3 and polycystic kidney disease-causing ARPKD1 [164]. Elegant murine studies have unraveled the role of cilia and crosstalk with the Hhsignaling pathway in the development of skin tumors of the basal cell carcinoma (BCC) subtype [165] and subtypes of medulloblastoma brain tumors [166]. These studies collectively demonstrate in vivo that cilia can either promote or repress tumor formation, but depletion of cilia formation alone is not sufficient to drive tumor formation, and tumor development requires driving oncogenic mutation of Hh-components [167]. BCC, medulloblastoma and other cancers, including pancreatic and ovarian cancers described above, often upregulate Hh-signaling. In tumors driven by upstream mutations in the Hh pathway (Ptc, Smo, Sufu or excessive Hh-ligand), the cilium is required to process GliA and activate downstream targets [151]. Intriguingly, in mutants driven by oncogenic Smo, simultaneous blocking of cilia formation by knocking out Kif3a or Ift88, resulted in impaired GliA formation and inhibition of tumorigenesis, suggesting that in this model, tumor formation is cilia-dependent $[165,166]$. If tumor formation is caused by mutations downstream of cilia (Gli1A, Gli2A), cilia are obsolete for Hh activation. However, restored ciliation dampens Hh-signaling, which is explained by the formation of Gli3R that counteracts GliA [151]. Thus, selection for the presence or absence of cilia of these cancer types entirely depends on the underlying oncogenic mutation. Medulloblastomas featuring oncogenic mutations in $\beta$-catenin also retain cilia, indicating that cilia function is still required for tumor formation. Although cilia generally reduce $\beta$-catenin nuclear-signaling, which would place selective pressure for cilia-loss in tumors, it is possible that a threshold level of Hh-signaling is still required in some tumor types, leading to cilia retention [166]. On a more general note, tumors that depend on cilia retention seem to have better prognosis with regard to survival [166]. In addition to these cellautonomous $\mathrm{Hh}$ effects, increased $\mathrm{Hh}$-signaling through autocrine or paracrine signals from the tumor stroma adds another layer of complexity [168].

Cilia loss is prevalent in various forms of kidney cancer. Renal cysts are a hallmark phenotype of cilia dysfunction and prevalent in many classic ciliopathy syndromes [49]. Accumulating evidence suggests that renal cystic lesions are a precursor stage of tumor formation; patients with acquired cystic kidney disease (ACKD) have an increased risk for renal cancer with incidences ranging from 2 to $5 \%$ [169]. It was recently demonstrated that chronic lithium therapy (a standard therapy for bipolar disorder) increased the risk for ACKD and kidney cancer development; lithium activates GSK3 $\beta$ by phosphorylation, resulting in increased $\beta$-catenin-signaling, which is known to suffice 
for renal cyst formation $[87,170]$. Renal cell carcinoma (RCC) can be subdivided into clear cell RCC (ccRCC), chromophobe (chrRCC) and papillary RCC (pRCC) subtypes [171,172]. Renal oncocytoma closely resembles the chrRCC pathology $[173,174]$, and both tumor types arise from unciliated intercalated cells of the renal collecting duct. Analysis of a small cohort of ccRCC indicated severely reduced cilia frequencies and a more subtle reduction in pRCC [175], our own results, in a large group of ccRCC compared to parenchymal tissue confirmed this and also indicated reduced frequencies in oncocytomas and chrRCC [176]. Both studies excluded the possible confounder that the fewer cilia observed were due to increased cell proliferation through scoring for Ki67positive cells $[175,176]$. Intriguingly, cancer syndromes that predispose to RCC development, encoded for by mutant VHL, FLCN or TSC1/2 (discussed in greater detail in a separate section), all have been shown to assert molecular activity towards cilia function and structure in addition to their previously recognized functions in relaying responses to metabolic factors. This puts forward the hypothesis that kidney cancer is a two-step process in which both primary cilium function needs to be impaired as well as modification of metabolic pathways; uncoupling regulation by energy, nutrients, oxygen and iron. Of interest, in a family predisposed to RCC and thyroid cancer, a genomic breakpoint was identified disrupting TRC8, a protein related to $\mathrm{PTCH}$ [177].

\section{Familial cancer syndromes and cilia}

Genetic predisposition to solid tumor development is typically associated with heterozygous germline mutations in tumor suppressor genes or oncogenes. Identifying the genes and pathways mutated in these rare cancer syndromes has been proven remarkably useful in understanding early events of tumor development. Because a single patient with a germline mutation may have several lesions of varying degrees, it is possible to understand the genetic and cellular contribution to the natural course of that particular tumor type. Functional aspects of many of these genes have been elucidated, and interestingly, a number of well- established classic tumor suppressor proteins are involved in ciliary biogenesis, in addition to their attributed functions. The fundamental processes underlying cancer development and the tissues targeted in these syndromes are likely to require modulation of multiple cellular processes prior to carcinogenesis. Yet, the association of several classic tumor suppressor proteins and cilia suggests that ciliary loss, at least in some tissues like perhaps the kidney, can be associated with very early events in tumorigenesis.

For example, mutations in the $V H L$ tumor suppressor cause the autosomal dominant familial cancer syndrome von Hippel-Lindau disease (VHL) that is characterized by the development of renal and pancreatic cysts, ccRCC, pheochromocytoma (tumor of the adrenal gland), cysts and hemangiomas in the central nervous system, retinal angiomas, and low-grade adenocarcinomas of the temporal bone [178]. In addition, $V H L$ is also inactivated in up to $87 \%$ of sporadic clear cell RCC's [179]. VHL loss conforms to the Knudson 2-hit model that dictates that both wild-type alleles of a tumor suppressor gene must be inactivated prior to tumor outgrowth [180]. Depending on the germline mutation resulting in complete loss-offunction or missense hypomorphic mutations, the disease is manifested in a subset or combination of target organs. VHL's biological activity is complex; one major role is the degradation of HIF transcription factors, which become stabilized in hypoxic conditions and regulate the activation of a transcriptional program that promotes angiogenesis [164]. Given that artificially high activity of HIFs is not sufficient for RCC development [181], VHL must exert alternative protein functions. HIF-independent functions of VHL include regulation of cell polarity through Par3, Par6 and stabilization and orientation of microtubules [182]. Interestingly, VHL binds kinesin-2 subunits KIF3A and KAP, and it facilitates renal cilia mechanosensation [164]. Moreover, VHL seems to act in conjunction with GSK3 $\beta$ to maintain cilia; depletion of either protein alone does not affect ciliation, but activation of GSK3 $\beta$ in the absence of VHL initiates cilia disassembly [183]. The current view is that loss of VHL is sufficient for renal cyst formation, but that additional genetic lesions are required for subsequent degeneration of a renal cyst into ccRCC $[164,180]$. The observation that mice with inactivated Vhlh and Pten develop epididymal cystadenomas supports this model [184]. The chance of acquiring additional inactivating alleles at other loci is promoted by $V H L$ loss, given that loss of VHL also reduces Mad2 levels, a protein that is part of the spindle checkpoint [185]. Aneuploidy and chromosomal instability drive subsequent genetic changes associated with RCC.

Tuberous sclerosis (TSC) is an autosomal dominant disorder that associates with neurologic disorders such as epilepsy, mental retardation and autism, but is mainly a tumor suppressor gene syndrome associated with renal cyst formation and tumorigenesis in various organs including the kidney, brain, retina and skin $[186,187]$. TSC is associated with germline mutations in TSC1/Harmatin and TSC2/Tuburin [188]. Renal phenotypes in TSC patients mostly comprise benign renal angiomyolipoma (50 to $80 \%$ ), but a minority develops ccRCC (3\%) [169]. Although the overall ccRCC incidence is only marginally increased compared to the general population, the onset of ccRCC development in TSC patients seems to occur earlier in life and other RCC pathologies are sometimes also observed [187]. Mouse models similarly develop cysts and RCC [189-191]. TSC disease manifestation requires 
genetic inactivation of the second allele of either TSC1 or $T S C 2$, rendering it a classic tumor suppressor gene. In contrast to VHL, loss of Tsc1 or Tsc2 enhances cilia length in mouse MEF's and zebrafish mutants [186,192], which could explain why TSC patients clinically exhibit few renal cysts and relatively low RCC frequency [188]. The increased cilia length fits with the finding that disruption of a number of neurologic disorder-associated genes similarly enhance cilia length [54]. The mTOR pathway senses nutrient and energy levels and regulates cell growth accordingly. TSC 1 and TSC 2 normally form a heterodimer TSC $1 / 2$ that inhibits the TORC 1 complex. Blocking the mTORC1 complex using rapamycin reduces cilia length, suggestive of a role for nutrient/energy-sensing in cilia length control [193]. The TORC1 complex functions upstream of the S6 kinase 1 (S6K1) which regulates ribosomal function and translation. Overexpression of $s 6 k 1$ in zebrafish also increases cilia length, making it likely that the TORC1 complex regulates cilia length through S6K1. Thus, loss of TSC1/2 releases the repression of TORC1, activating S6K1 and increasing cilia length [193]. In addition, GSK3 $\beta$ was found to function as an upstream activator of TORC1 [193]. The emerging view thus suggests that low energy/nutrient levels activates the mTOR pathway and via S6K1 enhances cilia length, which physically delays the cell cycle in a similar fashion to Nde1 and Tctex1 [140,141].

Functioning in the same nutrient/energy-sensing pathway is FLCN, which is the gene product of the disease locus for the monogenic disorder Birt-Hogg-Dubé (BHD) syndrome [194]. BHD syndrome is characterized by the development of renal cysts, kidney tumors of various histopathological subtypes, pulmonary cysts and benign cutaneous tumors (fibrofolliculomas) [195]. Renal tumors isolated from BHD patients are histologically diverse, predominantly consisting of chrRCC (34\%) and hybrid oncocytoma/chromophobe (50\%) neoplasms (both derived from intercalated cells of the collecting duct), and less frequently ccRCC (9\%) [196]. Accordingly, mouse mutants for BHD-syndrome form renal cysts and RCC [197]. We have shown that FLCN levels affect ciliation [195,198]. In contrast to TSC1/2, FLCN does not affect cilia length but rather regulates the timing of ciliation. FLCN-associated cilia loss results in increased $\beta$-catenin-signaling and loss of FLCN additionallyinduced PCP defects, which could explain the renal cystic phenotype in BHD patients [195,198]. FLCN has further been described to signal to AMPK, TSC1/2 and TORC1, however there is conflicting data and it remains uncertain whether FLCN activates or inhibits the mTOR pathway. In mouse renal tumors, loss of FLCN activates TSC1/2 [199]. It has been suggested that inappropriately high as well as low levels of TORC can lead to renal tumor formation [200], however, the precise role of ciliary-signaling in these events remains elusive.
Another member of the energy/nutrient-sensing pathway is the kinase LKB1, encoded for by STK11. Mutations in STK11 predispose to the Peutz-Jeghers tumor syndrome (PJS) that features benign gastrointestinal (GI) polyps as well as malignant tumors in the GI, breast and gynecological organs. Somatic STK11 mutations have been identified in lung, bladder and cervical cancer [201]. LKB1 is a master regulator of numerous downstream kinases, including AMPK and is upstream of mTOR-signaling [201]. Simultaneous inactivation of $l k b 1$ and $v h l$ in zebrafish, however, neutralizes AMPK activation and the $l k b 1$ phenotype, suggesting a complex interplay between hypoxia and AMPK pathways [202]. The role of cilia in LKB1 regulation is currently limited, however it has been shown that cilia mechanosensation under flow conditions requires ciliary-localized Lkb1 to activate AMPK and mTOR-signaling to regulate cell size. This effect is independent of $\mathrm{Ca}^{2+}$-mediated mechanosensation [203]. Similar to FLCN and VHL, LKB1 and IFT88 independently regulate spindle positioning in epithelial cells $[96,185,204]$.

Mosaic variegated aneuploidy syndrome (MVA) is a rare autosomal recessive childhood cancer disorder characterized by mosaic aneuploidies that give rise to rhabdomyosarcoma, Wilms' tumor/polycystic nephroblastoma and leukemia [205]. Associated pathologies overlap with the ciliopathy disease spectrum; polycystic kidneys, microcephaly, Dandy-Walker complex, intrauterine growth retardation, mental retardation, infantile obesity, congenital abnormalities, eye abnormalities, postcerebellar cyst and hypoplasia of the cerebellar vermis [206,207]. MVA can be caused by biallelic as well as monoallelic mutations in $B U B 1 B$ and CEP57 [205]. BUB1B encodes for the spindle checkpoint protein BUBR1, defects in which cause premature chromosome segregation errors and neuploidy in vitro [208]. A recently identified additional function for BUBR1 is the regulation of ciliogenesis. Quiescence is maintained through proteasomal degradation of a number of substrates including DVL. Basal DVL activity is required for basal body docking and ciliogenesis, however, increased activity leads to downstream canonical Wntactivation and cell cycle progression. In control and MVA patient-derived fibroblasts, BUBR1 was identified as an essential co-activator of the $\mathrm{APC} / \mathrm{C}^{\mathrm{CDC} 20}$ complex that targets $\mathrm{CDC} 20$ for degradation and allows the $\mathrm{APC} / \mathrm{C}^{\mathrm{CDH} 1}$ to maintain low DVL levels during quiescence through proteasomal degradation. Consequently, high levels of DVL in MVA-cells inhibit ciliogenesis. The inability of BUBR1 to bind $\mathrm{CDC} 20$ and inhibit $\mathrm{APC} / \mathrm{C}^{\mathrm{CDC} 20}$ also disturbs the spindle assembly checkpoint and subsequent faithful chromosome segregation [207].

Basal cell nevus syndrome or Gorlin syndrome is a rare autosomal dominant disorder with an estimated incidence of 1 in 57,000, and is characterized by a variable disease spectrum including macrocephaly, frontal bossing, 
hypertelorism, skeletal defects, palmar pits and predisposition for BCC and medulloblastoma development [209]. Mutations have been identified in hedgehog components, mostly located to PTCH1. Also, in sporadic BCC and medulloblastoma, mutations in Hh-components, including PTCH2, SUFU and SMO, have been demonstrated [210]. As described above, hedgehog-signaling is dependent on intact cilia to appropriately process GliA and GliR.

One of the most frequently mutated genes in somatically acquired colorectal cancer is the $A P C$ tumor suppressor which, if mutated in the germline, causes familial adenomatous polyposis (FAP). One subtype of FAP is Gardner's syndrome characterized by frequent extracolonic manifestations such as osteomas, skin cysts, desmoid tumors and retinal abnormalities [211]. This disease spectrum overlaps with ciliopathy disease characteristics and suggests a role for APC in cilia function. In addition, retrospective studies noted that most patients with FAP display extracolonic ciliopathy phenotypes of varying severity [211]. APC can bind the kinesin-2 member Kif3a and microtubule binding protein EB1, both essential for ciliation [212,213]. In addition, APC interacts with EB1 and KIF17 and stabilizes microtubule plus-ends [214].

In addition to the tumor suppressors in familial cancer development described above, a number of additional tumor suppressors and oncogenes, not directly associated with familial cancer syndromes but often somatically mutated in sporadic cancers, also can affect cilia biogenesis. Members of the Wnt- and Hh-signaling pathway that have somatically acquired oncogenic activity such as $\beta$-catenin, Ptc, Smo, Sufu and Gli lead to aberrant transcription of target genes, which is a constituent in many cancer types [68]. The NEK family is composed of serine-threonine kinases involved in cell cycle regulation and cancer formation. NEK1, NEK2 and NEK8/NPHP9 are related to ciliary biogenesis $[215,216]$. Mouse models affecting either NEK1 or NEK8 protein function show phenotypic overlap with ciliopathies $[217,218]$. Inactivation of $N E K 1$ was recently associated with the human ciliopathy autosomal-recessive short-rib polydactyly syndrome [219]. Mutations in NEK1, NEK2 and NEK 8 have been identified in liver, ovarian, GI and lung cancers [215]. Furthermore, NEK8/NPHP9 was recently shown to directly bind the oncogenic transcriptional activator TAZ [157], as was also reported for transition zone component NPHP4 [106]. These findings are exciting since the Hippo pathway comprises a number of proteins that act as a tumor suppressor network in the control of organ size and growth control [105].

\section{Chromosomal instability and cilia}

The cell makes use of an elaborate and elegant system of checkpoints to prevent and counteract cellular transformation and cancerous outgrowth. These include the mitotic or spindle checkpoint, as well as the DNA-damage checkpoints. Failure of these control systems leads to an accumulation of errors that eventually will result in chromosomal instability, a major driver of cancer progression. With the exception of certain terminally differentiated cell types, only one centrosome is present per quiescent cell. Upon duplication in S-phase, centrosomes migrate to opposing sides of the cell where they form spindle poles during mitosis. Although cells are still able to successfully segregate their chromosomes in the complete absence of centrosomes, centrosomal abnormalities can have severe effects on cells, ranging from defective spindle orientation, ineffective asymmetric cell division and cancer. Defects in centrosome separation or overreplication of centrosomes drive aneuploidy [116]. Similarly, when cytokinesis is perturbed, cells can inherit abnormal centrosome numbers. In addition, cells inheriting multiple centrosomes will form an equivalent number of cilia, which will distort signal interpretation [220]. Centrosomal abnormalities are a prominent feature of human tumors [220]. There are obviously many regulators of correct centrosome duplication and cytokinesis; here we will only discuss the crossroads between cilia biology and cancer development. Cilia defects in the kidney often lead to cyst formation, and these cysts can be considered benign neoplasms as they present hyperplasia; however, the incidence of tumor development in patients with cystic ciliopathies is low, and a second event is likely required for tumor growth initiation.

There is some emerging evidence that cilia defects can be linked to mitotic abnormalities. Murine endothelial cells derived from $P k d 2$ and Orpk/Ift88 knockout mice in addition to cell samples derived from human ADPKD patients had multipolar spindles and centrosomal abnormalities are observed that lead to polyploidy and chromosomal instability. Further analysis of these cells indicated that the chromosomal passenger complex protein survivin was down-regulated [221]. As discussed above, BUBR1 functions both in mitotic and ciliogenesis control [207], and interestingly, another member of the spindle assembly checkpoint, Mps1, has recently been shown to also affect ciliogenesis [222]. In cycling cells, depletion of either Mps1 or its direct interaction partner VDAC3 induces aberrant ciliogenesis, and upon serum starvation localization of Mps1 to the centrosome is sufficient to suppress ciliogenesis in RPE cells, suggesting it is a negative regulator of ciliation [222]. It would be interesting to study other components of the spindle checkpoint, such as the MAD proteins, for putative roles in ciliogenesis. Several other cell culture-based studies support a mechanism that could explain the induction of centrosomal abnormalities in cilia-related proteins; we previously reported that there is a large proteomic overlap between ciliogenesis and cytokinesis, including members of the chromosomal passenger complex [126], indicating that defects in these proteins can affect ciliogenesis as well as mitosis. As described in 
more detail above, oncogenic activation of HEF1 and downstream Aurora A induce premature cilia resorption and induce centrosomal over-replication [127]. Indeed, disruption of several cilia-related genes stimulates inappropriate cell cycle progression that can develop into replication stress. The IFT motor kinesin-2 does not exclusively function in cilia, but is also pivotal for normal mitosis; mutant KIF3B induces aneuploidy and induces multipolar spindle formation in NIH3T3 cells [223]. In addition, the KIF3 complex functions as a tumor suppressor in embryonic brain tumors, and Kap3-/- MEFs fail to transport cadherin complexes to the membrane and to inhibit downstream $\beta$-catenin activity [224].

The accumulation of DNA damage over time similarly increases the risk of cell transformation and cancer development. Cellular checkpoints normally prevent cells from proliferation under these conditions; this is regulated through the DNA damage response pathway, which is largely mediated by ATM and ATR [225]. The centrosomal proteins CEP152 and PCNT are required for ATRdependent DNA damage response-signaling. Mutations in these genes lead to Seckel syndrome that is characterized by dwarfism, microcephaly and mental retardation, phenotypically overlapping somewhat with the ciliopathy disease spectrum [226]. Recently, we and others have shown that mutations in SDCCAG8, ZNF423 and CEP164 cause a NPHP-related ciliopathy and that these proteins localize to both the centrosome and DNA damage foci, and are required for proper DNA damage-induced response $[226,227]$. CEP164 is a well known regulator of cilia formation and is one of the earliest proteins that defines a matured centriole by the formation of distal appendages [228]. In addition, we have seen that Cep164 loss not only induces DNA damage response but also induces DNA damage in the form of lagging anaphases, probably resulting in mitotic catastrophe. Induced DNA damage by irradiation causes premature centriole splitting [229]. The resulting centriolar clusters sustain ciliogenesis, but upon depletion of centriolar linker proteins C-NAP1 or rootletin, ciliogenesis is perturbed [230]. It would be of interest to further study the defective cilia/DNA damage response crosstalk in light of cancer biology.

\section{Metastasis}

Cell migration occurs generally in early development, wound-healing and chemotaxis. In aggressive cancers, transformed cells detach from the primary tumor and migrate throughout the body to form distant metastases. Cell migration is a multi-step process that partially depends on highly dynamic actin rearrangements, loss of focal adhesions, lamellipodia formation and changes of cell-matrix interaction [231]. In this light it is also of interest that Aurora A activator HEF1 regulates focal adhesions and is a prometastatic factor with elevated expression in melanoma and glioblastomas [127]. Cilia regulate normal cell migration in wound healing in response to the PDGFAA chemokine, and fibroblasts defective in primary cilia fail to initiate chemotaxis [102]. It was observed that cilia are often oriented towards the direction of migration, suggesting that cilia provide context for directed cell migration [103]. Endothelial cells derived from the Ift88-/oak ridge polycystic kidney mouse model showed reduced F-actin stress fibers, reduced focal adhesions and impaired cell migration due to down-regulated Hsp27 and focal adhesion kinase (FAK). Endothelial cells derived from Pkd1 (PC1) deficient mice did not show these defects, indicating that normal ciliation is involved in this process [232]. Finally, in an RNA interference screen in MCF-10A cells, NEK8 depletion was identified as a potent inducer of induced cell migration [233]. There are however many different signal transduction pathways that at various levels contribute to cellular migration, such as cell-matrix interactions, cell polarity and receptors dispersed across the plasma membrane rather than being enriched in the cilium. In the years to come, there will likely be an expansion of our understanding of the role of cilia in cell migration, and hence how, and if, defects in ciliary-signaling might affect cancer metastasis formation.

\section{Conclusions/perspectives}

Because of the tremendous efforts made to dissect ciliary function, the level of data depth has now reached a point where we can appreciate the subtle reality that the cilium both taps into and cross-talks with many classical molecular signaling pathways, coordinating and fine-tuning cellular responses. Cancer development is a multi-step process that does not depend on one singular event, but is suggested to require the sequestration of at least six capabilities that allow survival and outgrowth. These include (1) desensitization to anti-proliferative signals and (2) replicative stress, (3) escape from apoptosis, (4) acquisition of sustained angiogenesis and (5) metastasis potential and (6) autonomous generation of proliferative signals. To achieve this, cancer cells must promote chromosomal instability followed by continuous trial-and-error before the required capabilities have been acquired [234]. Therefore the proclamation that tumorigenesis is a bona fide ciliopathy, or whether the cilium is a bona fide tumor suppressor, can be rejected, as neither of the two is correct. Depending on the oncogenic event, cells will either select for cilia retention or disposal and are thus upstream or downstream of cancer development. In Figure 5 we describe ways the cilium might function in tumorigenesis. Most cells normally establish a cilium and are able to interpret environmental sensing such as contact signals or metabolic factors including nutrient, oxygen and $\mathrm{Ca}^{2+}$ levels. Step 1: cilia are lost and will result in a benign neoplasm with limited overproliferation and polarity defects. Step 2: environmental 


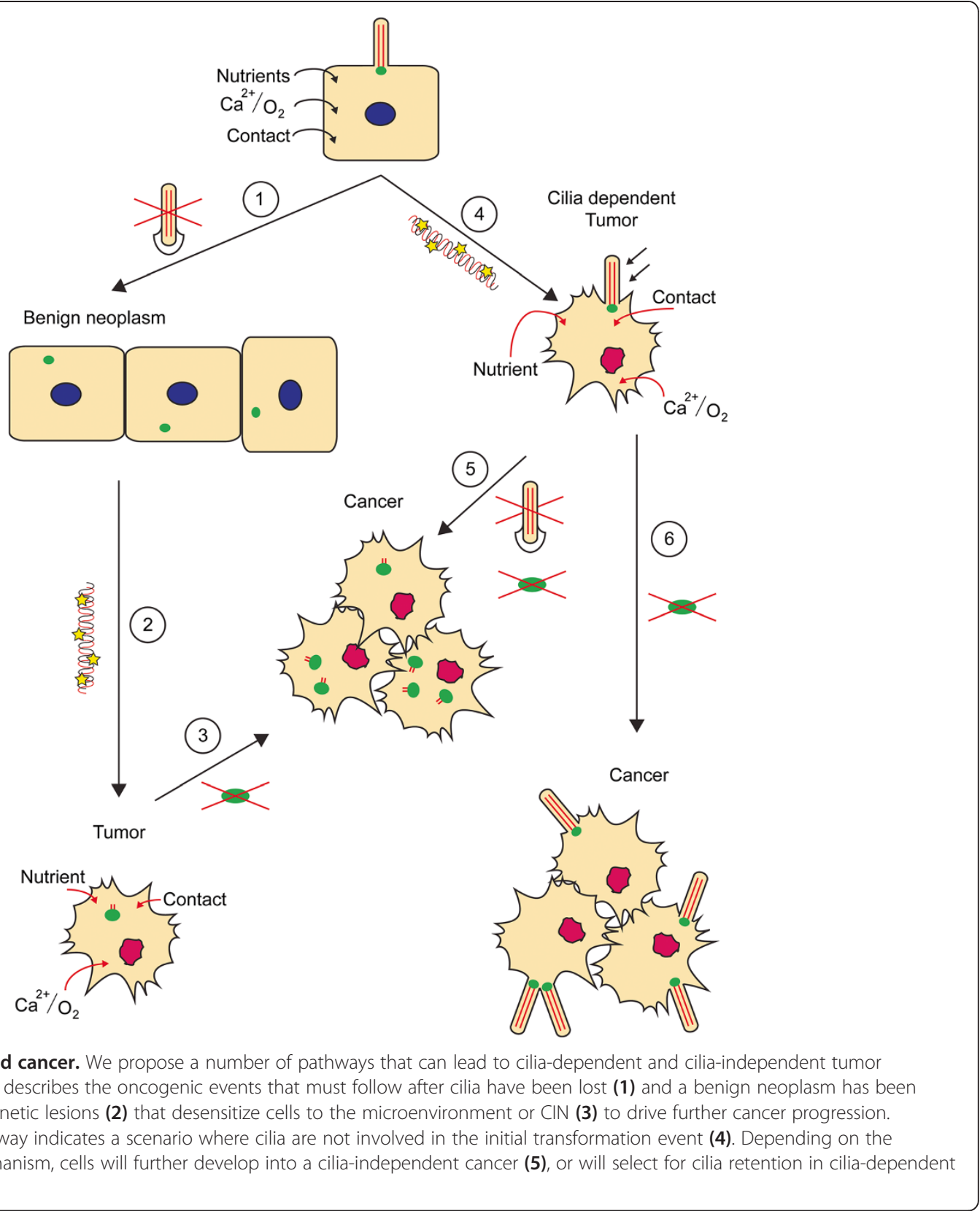

sensing is lost and cells transform. Step 3: cumulative DNA damage and replicative stress induce chromosome instability and lead to malignant cancer. Based on the clinical observation described above, the trend in most cancers seems to be in accordance with steps 1 to 3 . Step 4: alternatively, cells transform but remain dependent on ciliary signaling. Steps 5 and 6: these tumors can acquire chromosomal instability and either dispose of (5), or retain (6), cilia to become cancerous. Cataloging various tumor subtypes and relating these to ciliation frequency scores might be an important next step in relation to future therapeutic approaches. Tumors that depend on cilia function, for example Hh-mediated tumors, might benefit from complementary treatment with Aurora A activators which promote cilia disassembly and therefore dampen Hh-signaling, or targeting downstream Hh transcription factors. Alternatively, tumors that select for cilia disposal might benefit from treatment with cilia-stabilizing molecules such as low-dose taxol and HDAC-inhibitors. Low-dose paclitaxel stabilizes microtubules and cilia and ameliorates renal fibrosis in rats [235]. For extensive reviews on putative therapeutic approaches we refer to excellent surveys by Scales and de Sauvage [168] and Hassounah, Bunch and McDermott [151]. Thus, although the cilium does not 
single-handedly drive or prohibit tumorigenesis by default, targeting its function could be a method to switch cancer off.

\section{Abbreviations}

ACKD: Acquired cystic kidney disease; BB: Basal body; CNS: Central nervous system; GAP: Guanine activating proteins; GEF: Guanine exchange factors; Hh: Hedgehog-signaling; IFT: Intraflagellar transport; PCP: Planar cell polarity; TZ: Transition zone.

\section{Competing interests}

Both authors declare that they have no competing interests.

\section{Authors' contributions}

SB and RG wrote the paper. Both authors read and approved the final manuscript.

\section{Acknowledgements}

SB was financially supported by grants from '3 Lichten' foundation, Rene Vogels Dutch Association for Oncology foundation, Company for Biologists and the Dutch Cancer Society. RG is supported by the Netherlands Organization for Scientific Research (NWO Vidi-917.66.354) and the European Community's Seventh Framework Program FP7/2009 under grant agreement nunber: 241955, SYSCILIA.

\section{Author details}

${ }^{1}$ Department of Medical Oncology, UMC Utrecht, Universiteitsweg 100, 3584 CG, Utrecht, The Netherlands. 'Department of Nephrology and Hypertension, University Medical Center Utrecht, Heidelberglaan 100, F03.223, 3584 CX, Utrecht, The Netherlands.

\section{Received: 30 November 2012 Accepted: 25 March 2013}

\section{Published: 29 April 2013}

\section{References}

1. Fliegauf M, Benzing T, Omran H (2007) When cilia go bad: cilia defects and ciliopathies. Nat Rev Mol Cell Biol 8:880-893

2. Stearns T (2001) Centrosome Duplication: A Centriolar Pas de Deux. Cell 145:417-420

3. Schmidt KN, Kuhns S, Neuner A, Hub B, Zentgraf H, Pereira G (2012) Cep164 mediates vesicular docking to the mother centriole during early steps of ciliogenesis. J Cell Biol 199:1083-1101

4. Dawe HR, Adams M, Wheway G, Szymanska K, Logan CV, Noegel AA, Gull K, Johnson CA (2009) Nesprin-2 interacts with meckelin and mediates ciliogenesis via remodeling of the actin cytoskeleton. J Cell Sci 122:2716-2726

5. Reiter JF, Blacque OE, Leroux MR (2012) The base of the cilium: roles for transition fibers and the transition zone in ciliary formation, maintenance and compartmentalization. EMBO Rep 13:608-618

6. Kobayashi T, Tsang WY, Li J, Lane W, Dynlacht BD (2011) Centriolar kinesin Kif24 interacts with CP110 to remodel microtubules and regulate ciliogenesis. Cell 145:914-925

7. Goetz SC, Liem KF, Anderson KV (2012) The spinocerebellar ataxia-associated gene tau tubulin kinase-2 controls the initiation of ciliogenesis. Cell 151:847-858

8. Kim J, Lee JE, Heynen-Genel S, Suyama E, Ono K, Lee K, Ideker T, Aza-Blanc P, Gleeson JG (2010) Functional genomic screen for modulators of ciliogenesis and cilium length. Nature 464:1048-1051

9. Schrøder JM, Larsen J, Komarova Y, Akhmanova A, Thorsteinsson RI, Grigoriev I, Manguso R, Christensen ST, Pedersen SF, Geimer S, Pedersen LB (2011) EB1 and EB3 promote cilia biogenesis by several centrosome-related mechanisms. J Cell Sci 124:2539-2551

10. Hsiao Y-C, Tuz K, Ferland RJ (2012) Trafficking in and to the primary cilium. Cilia 1:4

11. Jin H, White SR, Shida T, Schulz S, Aguiar M, Gygi SP, Bazan JF, Nachury MV (2012) The conserved Bardet-Biedl syndrome proteins assemble a coat that traffics membrane proteins to cilia. Cell 141:1208-1219

12. Westlake CJ, Baye LM, Nachury MV, Wright KJ, Ervin KE, Phu L, Chalouni C, Beck JS, Kirkpatrick DS, Slusarski DC, Sheffield VC, Scheller RH, Jackson PK (2011) Primary cilia membrane assembly is initiated by Rab11 and transport protein particle II (TRAPPII) complex-dependent trafficking of Rabin8 to the centrosome. Proc Natl Acad Sci 108:2759-2764
13. Ishikawa H, Marshall WF (2011) Ciliogenesis: building the cell's antenna. Nat Rev Mol Cell Biol 12:222-234

14. Molla-Herman A, Ghossoub R, Blisnick T, Meunier A, Serres C, Silbermann F, Emmerson C, Romeo K, Bourdoncle P, Schmitt A, Saunier S, Spassky N, Bastin P, Benmerah A (2010) The ciliary pocket: an endocytic membrane domain at the base of primary and motile cilia. J Cell Sci 123:1785-1795

15. Benmerah A (2012) The ciliary pocket. Curr Opin Cell Biol 25:1-7

16. Yang J, Li T (2005) The ciliary rootlet interacts with kinesin light chains and may provide a scaffold for kinesin-1 vesicular cargos. Exp Cell Res 309:379-389

17. Garcia-Gonzalo FR, Reiter JF (2012) Scoring a backstage pass: mechanisms of ciliogenesis and ciliary access. J Cell Biol 197:697-709

18. Kee HL, Dishinger JF, Lynne Blasius T, Liu CJ, Margolis B, Verhey KJ (2012) A size-exclusion permeability barrier and nucleoporins characterize a ciliary pore complex that regulates transport into cilia. Nat Cell Biol 14:431-437

19. Deane JA, Cole DG, Seeley ES, Diener DR, Rosenbaum JL (2001) Localization of intraflagellar transport protein IFT52 identifies basal body transitional fibers as the docking site for IFT particles. Curr Biol 11:1586-1590

20. Sang L, Miller JJ, Corbit KC, Giles RH, Brauer MJ, Otto EA, Baye LM, Wen X, Scales SJ, Kwong M, Huntzicker EG, Sfakianos MK, Sandoval W, Bazan JF, Kulkarni P, Garcia-Gonzalo FR, Seol AD, O'Toole JF, Held S, Reutter HM, Lane WS, Rafiq MA, Noor A, Ansar M, Devi ARR, Sheffield VC, Slusarski DC, Vincent JB, Doherty DA, Hildebrandt F, et al. (2001) Mapping the NPHP-JBTS-MKS protein network reveals ciliopathy disease genes and pathways. Cell 145:513-528

21. Williams CL, Li C, Kida K, Inglis PN, Mohan S, Semenec L, Bialas NJ, Stupay RM, Chen N, Blacque OE, Yoder BK, Leroux MR (2011) MKS and NPHP modules cooperate to establish basal body/transition zone membrane associations and ciliary gate function during ciliogenesis. J Cell Biol 192:1023-1041

22. Valente EM, Logan CV, Mougou-Zerelli S, Lee JH, Silhavy JL, Brancati F, lannicelli M, Travaglini L, Romani S, Illi B, Adams M, Szymanska K, Mazzotta A, Lee JE, Tolentino JC, Swistun D, Salpietro CD, Fede C, Gabriel S, Russ C, Cibulskis K, Sougnez C, Hildebrandt F, Otto EA, Held S, Diplas BH, Davis EE, Mikula M, Strom CM, Ben-Zeev B, et al. (2010) Mutations in TMEM216 perturb ciliogenesis and cause Joubert, Meckel and related syndromes. Nat Genet 42:619-625

23. Huang L, Szymanska K, Jensen VL, Janecke AR, Innes AM, Davis EE, Frosk P, Li C, Willer JR, Chodirker BN, Greenberg CR, McLeod DR, Bernier FP, Chudley AE, Müller T, Shboul M, Logan CV, Loucks CM, Beaulieu CL, Bowie RV, Bell SM, Adkins J, Zuniga FI, Ross KD, Wang J, Ban MR, Becker C, Nurnberg P, Douglas S, Craft CM, et al. (2011) TMEM237 is mutated in individuals with a Joubert syndrome-related disorder and expands the role of the TMEM family at the ciliary transition zone. Am J Hum Genet 89:713-730

24. Garcia-Gonzalo FR, Corbit KC, Sirerol-Piquer MS, Ramaswami G, Otto EA, Noriega TR, Seol AD, Robinson JF, Bennett CL, Josifova DJ, García-Verdugo JM, Katsanis N, Hildebrandt F, Reiter JF (2011) A transition zone complex regulates mammalian ciliogenesis and ciliary membrane composition. NPG 43:776-784

25. Srour M, Hamdan FF, Schwartzentruber JA, Patry L, Ospina LH, Shevell MI, Désilets V, Dobrzeniecka S, Mathonnet G, Lemyre E, Massicotte C, Labuda D, Amrom D, Andermann E, Sébire G, Maranda B, Consortium FC, Rouleau GA, Majewski J, Michaud JL (2012) Mutations in TMEM231 cause Joubert syndrome in French Canadians. J Med Genet 49:636-641

26. Christopher KJ, Wang B, Kong Y, Weatherbee SD (2012) Forward genetics uncovers Transmembrane protein 107 as a novel factor required for ciliogenesis and sonic hedgehog-signaling. Dev Biol 368:382-392

27. Hu Q, Milenkovic L, Jin H, Scott MP, Nachury MV, Spiliotis ET, Nelson WJ (2012) A septin diffusion barrier at the base of the primary cilium maintains ciliary membrane protein distribution. Science 329:436-439

28. Ward HH, Brown-Glaberman U, Wang J, Morita Y, Alper SL, Bedrick EJ, Gattone VH, Deretic D, Wandinger-Ness A (2011) A conserved signal and GTPase complex are required for the ciliary transport of polycystin-1. Mol Biol Cell 22:3289-3305

29. Follit JA, Li L, Vucica Y, Pazour GJ (2010) The cytoplasmic tail of fibrocystin contains a ciliary-targeting sequence. J Cell Biol 188:21-28

30. Dishinger JF, Kee HL, Jenkins PM, Fan S, Hurd TW, Hammond JW, Truong YN-T, Margolis B, Martens JR, Verhey KJ (2010) Ciliary entry of the kinesin-2 motor KIF17 is regulated by importin-beta2 and RanGTP. Nat Cell Biol 12:703-710

31. Mukhopadhyay S, Wen X, Ratti N, Loktev A, Rangell L, Scales SJ, Jackson PK (2013) The ciliary G-protein-coupled receptor Gpr161 negatively regulates the sonic hedgehog pathway via CAMP-signaling. Cell 152:210-223

32. Wright KJ, Baye LM, Olivier-Mason A, Mukhopadhyay S, Sang L, Kwong M, Wang W, Pretorius PR, Sheffield VC, Sengupta P, Slusarski DC, Jackson PK (2011) An ARL3-UNC119-RP2 GTPase cycle targets myristoylated NPHP3 to the primary cilium. Genes Dev 25:2347-2360 
33. Rosenbaum JL, Witman GB (2002) Intraflagellar transport. Nat Rev Mol Cell Biol 3:813-825

34. Verhey KJ, Dishinger J, Kee HL (2011) Kinesin motors and primary cilia. Biochem Soc Trans 39:1120-1125

35. Liem KF, Ashe A, He M, Satir P, Moran J, Beier D, Wicking C, Anderson KV (2012) The IFT-A complex regulates Shh-signaling through cilia structure and membrane protein trafficking. J Cell Biol 197:789-800

36. Zhao C, Omori Y, Brodowska K, Kovach P, Malicki J (2012) Kinesin-2 family in vertebrate ciliogenesis. Proc Natl Acad Sci 109:2388-2393

37. Insinna C, Pathak N, Perkins B, Drummond I, Besharse JC (2008) The homodimeric kinesin, Kif17, is essential for vertebrate photoreceptor sensory outer segment development. Dev Biol 316:160-170

38. Peden EM, Barr MM (2005) The KLP-6 kinesin is required for male mating behaviors and polycystin localization in Caenorhabditis elegans. Curr Biol 15:394-404

39. Liem KF, He M, Ocbina PJR, Anderson KV (2009) Mouse Kif7/Costal2 is a ciliaassociated protein that regulates Sonic hedgehog-signaling. Proc Natl Acad Sci 106:13377-13382

40. Oh EC, Katsanis N (2012) Cilia in vertebrate development and disease. Development 139:443-448

41. van Asselt SJ, de Vries EG, van Dullemen HM, Brouwers AH, Walenkamp AM, Giles RH, Links TP (2013) Pancreatic cyst development: insights from von Hippel-Lindau disease. Cilia 2:3

42. Louvi A, Grove EA (2011) Cilia in the CNS: the quiet organelle claims center stage. Neuron 69:1046-1060

43. Geerts WJC, Vocking K, Schoonen N, Haarbosch L, van Donselaar EG, Regan-Klapisz E, Post JA (2011) Cobblestone HUVECs: a human model system for studying primary ciliogenesis. I Struct Biol 176:350-359

44. Finetti F, Paccani SR, Rosenbaum J, Baldari CT (2011) Intraflagellar transport: a new player at the immune synapse. Trends Immunol 32:139-145

45. Hirokawa N, Tanaka Y, Okada Y, Takeda S (2006) Nodal flow and the generation of left-right asymmetry. Cell 125:33-45

46. Tobin JL, Beales PL (2009) The nonmotile ciliopathies. Genet Med 11:386-402

47. Pazour GJ, Dickert BL, Vucica Y, Seeley ES, Rosenbaum JL, Witman GB, Cole DG (2000) Chlamydomonas IFT88 and its mouse homologue, polycystic kidney disease gene tg737, are required for assembly of cilia and flagella. J Cell Biol 151:709-718

48. http://www.ffcbiol.org/Primaryciliumweb/.

49. Waters AM, Beales PL (2011) Ciliopathies: an expanding disease spectrum. Pediatr Nephrol 26:1039-1056

50. Hildebrandt F, Benzing T, Katsanis N (2011) Ciliopathies. N Engl J Med 364:1533-1543

51. D'Angelo A, Franco B (2011) The primary cilium in different tissues-lessons from patients and animal models. Pediatr Nephrol 26:655-662

52. Bredrup C, Saunier S, Oud MM, Fiskerstrand T, Hoischen A, Brackman D, Leh SM, Midtbø M, Filhol E, Bole-Feysot C, Nitschké P, Gilissen C, Haugen OH, Sanders J-SF, Stolte-Dijkstra I, Mans DA, Steenbergen EJ, Hamel BCJ, Matignon M, Pfundt R, Jeanpierre C, Boman H, Rødahl E, Veltman JA, Knappskog PM, Knoers NVAM, Roepman R, Arts HH (2011) Ciliopathies with skeletal anomalies and renal insufficiency due to mutations in the IFT-a gene WDR19. Am J Hum Genet 89:634-643

53. D'Angelo A, Franco B (2009) The dynamic cilium in human diseases. Pathogenetics 2:3

54. Marley A, von Zastrow M (2012) A simple cell-based assay reveals that diverse neuropsychiatric risk genes converge on primary cilia. PLoS One 7:e46647

55. Leigh MW, Pittman JE, Carson JL, Ferkol TW, Dell SD, Davis SD, Knowles MR, Zariwala MA (2009) Clinical and genetic aspects of primary ciliary dyskinesia/ Kartagener syndrome. Genet Med 11:473-487

56. Gherman A, Davis EE, Katsanis N (2006) The ciliary proteome database: an integrated community resource for the genetic and functional dissection of cilia. Nat Genet 38:961-962

57. Davis EE, Katsanis N (2012) The ciliopathies: a transitional model into systems biology of human genetic disease. Curr Opin Genet Dev 22:290-303

58. Nauli SM, Alenghat FJ, Luo Y, Williams E, Vassilev P, Li X, Elia AEH, Lu W, Brown EM, Quinn SJ, Ingber DE, Zhou J (2003) Polycystins 1 and 2 mediate mechanosensation in the primary cilium of kidney cells. Nat Genet 33:129-137

59. Ward CJ, Yuan D, Masyuk TV, Wang X, Punyashthiti R, Whelan S, Bacallao R, Torra R, LaRusso NF, Torres VE, Harris PC (2003) Cellular and subcellular localization of the ARPKD protein; fibrocystin is expressed on primary cilia. Hum Mol Genet 12:2703-2710
60. Low SH, Vasanth S, Larson CH, Mukherjee S, Sharma N, Kinter MT, Kane ME, Obara T, Weimbs T (2006) Polycystin-1, STAT6, and P100 function in a pathway that transduces ciliary mechanosensation and is activated in polycystic kidney disease. Dev Cell 10:57-69

61. Piontek K, Menezes LF, Garcia-Gonzalez MA, Huso DL, Germino GG (2007) A critical developmental switch defines the kinetics of kidney cyst formation after loss of Pkd1. Nat Med 13:1490-1495

62. Abdul-Majeed S, Nauli SM (2011) Calcium-mediated mechanisms of cystic expansion. BBA - Molecular Basis of Disease 10:1281-1290

63. Pietrobon M, Zamparo I, Maritan M, Franchi SA, Pozzan T, Lodovichi C (2011) Interplay among CGMP, CAMP, and Ca2+ in living olfactory sensory neurons in vitro and in vivo. J Neurosci 31:8395-8405

64. Kotsis F, Boehlke C, Kuehn EW (2013) The ciliary flow sensor and polycystic kidney disease. Nephrol Dial Transplant 3:518-526

65. Hoey DA, Downs ME, Jacobs CR (2012) The mechanics of the primary cilium: an intricate structure with complex function. J Biomech 45:17-26

66. Prodromou NV, Thompson CL, Osborn DPS, Cogger KF, Ashworth R, Knight MM, Beales PL, Chapple JP (2012) Heat shock induces rapid resorption of primary cilia. J Cell Sci 125:4297-4305

67. Wang Y, McMahon AP, Allen BL (2007) Shifting paradigms in hedgehog-signaling. Curr Opin Cell Biol 19:159-165

68. Tasouri E, Tucker KL (2011) Primary cilia and organogenesis: is hedgehog the only sculptor? Cell Tissue Res 345:21-40

69. Goetz SC, Anderson KV (2010) The primary cilium: a signaling center during vertebrate development. Nat Rev Genet 11:331-344

70. Tukachinsky H, Lopez LV, Salic A (2010) A mechanism for vertebrate hedgehog- signaling: recruitment to cilia and dissociation of SuFu-Gli protein complexes. J Cell Biol 191:415-428

71. Robbins DJ, Fei DL, Riobo NA (2012) The hedgehog signal transduction network. Sci Signal 5:re6

72. Wang B, Li Y (2006) Evidence for the direct involvement of \{beta\}TrCP in Gli3 protein processing. Proc Natl Acad Sci USA 103:33-38

73. Chen M-H, Wilson CW, Li Y-J, Law KKL, Lu C-S, Gacayan R, Zhang X, Hui C-C, Chuang P-T (2009) Cilium-independent regulation of Gli protein function by Sufu in hedgehog-signaling is evolutionarily conserved. Genes Dev 23:1910-1928

74. Humke EW, Dorn KV, Milenkovic L, Scott MP, Rohatgi R (2010) The output of hedgehog-signaling is controlled by the dynamic association between suppressor of fused and the Gli proteins. Genes Dev 24:670-682

75. Huangfu D, Liu A, Rakeman AS, Murcia NS, Niswander L, Anderson KV (2003) Hedgehog-signaling in the mouse requires intraflagellar transport proteins. Nature 426:83-87

76. Liu A, Wang B, Niswander LA (2005) Mouse intraflagellar transport proteins regulate both the activator and repressor functions of Gli transcription factors. Development 132:3103-3111

77. May SR, Ashique AM, Karlen M, Wang B, Shen Y, Zarbalis K, Reiter J, Ericson J, Peterson AS (2005) Loss of the retrograde motor for IFT disrupts localization of Smo to cilia and prevents the expression of both activator and repressor functions of Gli. Dev Biol 287:378-389

78. Cortellino S, Wang C, Wang B, Bassi MR, Caretti E, Champeval D, Calmont A, Jarnik M, Burch J, Zaret KS, Larue L, Bellacosa A (2009) Defective ciliogenesis, embryonic lethality and severe impairment of the sonic hedgehog pathway caused by inactivation of the mouse complex A intraflagellar transport gene Ift122/Wdr10, partially overlapping with the DNA repair gene Med1/Mbd4. Dev Biol 325:225-237

79. Tran PV, Haycraft CJ, Besschetnova TY, Turbe-Doan A, Stottmann RW, Herron BJ, Chesebro AL, Qiu H, Scherz PJ, Shah JV, Yoder BK, Beier DR (2008) THM1 negatively modulates mouse sonic hedgehog signal transduction and affects retrograde intraflagellar transport in cilia. Nat Genet 40:403-410

80. Gao C, Chen Y-G (2010) Dishevelled: the hub of Wnt-signaling. Cell Signal 22:717-727

81. Gerdes JM, Liu Y, Zaghloul NA, Leitch CC, Lawson SS, Kato M, Beachy PA, Beales PL, DeMartino GN, Fisher S, Badano JL, Katsanis N (2007) Disruption of the basal body compromises proteasomal function and perturbs intracellular Wnt response. Nat Genet 39:1350-1360

82. Corbit KC, Shyer AE, Dowdle WE, Gaulden J, Singla V, Reiter JF (2007) Kif3a constrains $\beta$-catenin-dependent Wnt-signalling through dual ciliary and non-ciliary mechanisms. Nat Cell Biol 10:70-76

83. Voronina VA, Takemaru K-I, Treuting P, Love D, Grubb BR, Hajjar AM, Adams A, Li F-Q, Moon RT (2009) Inactivation of Chibby affects function of motile airway cilia. J Cell Biol 185:225-233 
84. Kishimoto N, Cao Y, Park A, Sun Z (2008) Cystic kidney gene seahorse regulates cilia-mediated processes and Wnt pathways. Dev Cell 14:954-961

85. Otto EA, Schermer B, Obara T, O'Toole JF, Hiller KS, Mueller AM, Ruf RG, Hoefele J, Beekmann F, Landau D, Foreman JW, Goodship JA, Strachan T, Kispert A, Wolf MT, Gagnadoux MF, Nivet H, Antignac C, Walz G, Drummond IA, Benzing T, Hildebrandt F (2003) Mutations in INVS encoding inversin cause nephronophthisis type 2, linking renal cystic disease to the function of primary cilia and left-right axis determination. Nat Genet 34:413-420

86. Simons M, Gloy J, Ganner A, Bullerkotte A, Bashkurov M, Krönig C, Schermer B, Benzing T, Cabello OA, Jenny A, Mlodzik M, Polok B, Driever W, Obara T, Walz G (2005) Inversin, the gene product mutated in nephronophthisis type II, functions as a molecular switch between Wnt-signaling pathways. Nat Genet 37:537-543

87. Saadi-Kheddouci S, Berribe D, Romagnolo B, Cluzeaud F, Peuchmaur M, Kahn A, Vandewalle A, Perret C (2001) Early development of polycystic kidney disease in transgenic mice expressing an activated mutant of the b-catenin gene. Oncogene 42:5972-5981

88. Lancaster MA, Schroth J, Gleeson JG (2011) Subcellular spatial regulation of canonical Wnt-signalling at the primary cilium. Nat Cell Biol 13:702-709

89. Lancaster MA, Louie CM, Silhavy JL, Sintasath L, DeCambre M, Nigam SK, Willert K, Gleeson JG (2009) Impaired Wnt-beta-catenin-signaling disrupts adult renal homeostasis and leads to cystic kidney ciliopathy. Nat Med 15:1046-1054

90. Ocbina PJR, Tuson M, Anderson KV (2009) Primary cilia are not required for normal canonical Wnt-signaling in the mouse embryo. PLoS One 4:e6839

91. Huang P, Schier AF (2009) Dampened hedgehog-signaling but normal Wnt- signaling in zebrafish without cilia. Development 136:3089-3098

92. Chang C-F, Serra R (2012) Ift88 regulates hedgehog-signaling, Sfrp5 expression, and $\beta$-catenin activity in post-natal growth plate. J Orthop Res 3:350-356

93. Habas R, Dawid IB (2005) Dishevelled and Wnt-signaling: is the nucleus the final frontier? J Biol 4:2

94. Happé H, de Heer E, Peters DJM (2011) Polycystic kidney disease: the complexity of planar cell polarity and signaling during tissue regeneration and cyst formation. Biochim Biophys Acta 10:1249-1255

95. Wallingford JB, Mitchell B (2011) Strange as it may seem: the many links between Wnt-signaling, planar cell polarity, and cilia. Genes Dev 25:201-213

96. Delaval B, Bright A, Lawson ND, Doxsey S (2011) The cilia protein IFT88 is required for spindle orientation in mitosis. Nat Cell Biol 13:461-468

97. Singla V, Romaguera-Ros M, García-Verdugo JM, Reiter JF (2010) Ofd1, a human disease gene, regulates the length and distal structure of centrioles. Dev Cell 18:410-424

98. Kim JC, Badano JL, Sibold S, Esmail MA, Hill J, Hoskins BE, Leitch CC, Venner K, Ansley SJ, Ross AJ, Leroux MR, Katsanis N, Beales PL (2004) The Bardet-Biedl protein BBS4 targets cargo to the pericentriolar region and is required for microtubule anchoring and cell cycle progression. Nat Genet 36:462-470

99. Park TJ, Mitchell BJ, Abitua PB, Kintner C, Wallingford JB (2008) Dishevelled controls apical docking and planar polarization of basal bodies in ciliated epithelial cells. Nat Genet 40:871-879

100. Hoch RV, Soriano P (2003) Roles of PDGF in animal development. Development 130:4769-4784

101. Schneider L, Clement CA, Teilmann SC, Pazour GJ, Hoffmann EK, Satir P, Christensen ST (2005) PDGFRaa-signaling is regulated through the primary cilium in fibroblasts. Curr Biol 15:1861-1866

102. Schneider L, Cammer M, Lehman J, Nielsen SK, Guerra CF, Veland IR, Stock C, Hoffmann EK, Yoder BK, Schwab A, Satir P, Christensen ST (2010) Directional cell migration and chemotaxis in wound healing response to PDGF-AA are coordinated by the primary cilium in fibroblasts. Cell Physiol Biochem 25:279-292

103. Christensen ST, Clement CA, Satir P, Pedersen LB (2012) Primary cilia and coordination of receptor tyrosine kinase (RTK)-signaling. J Pathol 226:172-184

104. Neugebauer JM, Amack JD, Peterson AG, Bisgrove BW, Yost HJ (2009) FGF-signaling during embryo development regulates cilia length in diverse epithelia. Nature 458:651-654

105. Harvey K, Tapon N (2007) The Salvador-Warts-Hippo pathway - an emerging tumor-suppressor network. Nat Rev Cancer 7:182-191

106. Habbig S, Bartram MP, Müller RU, Schwarz R, Andriopoulos N, Chen S, Sägmüller JG, Hoehne M, Burst V, Liebau MC, Reinhardt HC, Benzing T, Schermer B (2011) NPHP4, a cilia-associated protein, negatively regulates the Hippo pathway. J Cell Biol 193:633-642

107. Grusche FA, Richardson HE, Harvey KF (2012) Upstream regulation of the hippo size control pathway. Curr Biol 20:R574-R582
108. Sfakianos J, Togawa A, Maday S, Hull M, Pypaert M, Cantley L, Toomre D, Mellman I (2007) Par3 functions in the biogenesis of the primary cilium in polarized epithelial cells. J Cell Biol 179:1133-1140

109. Tavares A, Gonçalves J, Florindo C, Tavares AA, Soares H (2012) Mob1: defining cell polarity for proper cell division. J Cell Sci 125:516-527

110. Happé $H$, van der Wal AM, Leonhard WN, Kunnen SJ, Breuning MH, de Heer E, Peters DJM (2011) Altered Hippo-signaling in polycystic kidney disease. J Pathol 224:133-142

111. Egorova AD, Khedoe PPSJ, Goumans M-JTH, Yoder BK, Nauli SM, ten Dijke P, Poelmann RE, Hierck BP (2011) Lack of primary cilia primes shear-induced endothelial-to-mesenchymal transition. Circ Res 108:1093-1101

112. Ezratty EJ, Stokes N, Chai S, Shah AS, Williams SE, Fuchs E (2011) A role for the primary cilium in Notch-signaling and epidermal differentiation during skin development. Cell 145:1129-1141

113. Mukhopadhyay S, Jackson PK (2011) The tubby family proteins. Genome Biol $12: 225$

114. Jacoby M, Cox JJ, Gayral S, Hampshire DJ, Ayub M, Blockmans M, Pernot E, Kisseleva MV, Compere P, Schiffmann SN, Gergely F, Riley JH, Perez-Morga D, Woods CG, Schurmans S (2009) INPP5E mutations cause primary cilium-signaling defects, ciliary instability and ciliopathies in human and mouse. Nat Genet 41:1027-1031

115. Bielas SL, Silhavy JL, Brancati F, Kisseleva MV, Al-Gazali L, Sztriha L, Bayoumi RA, Zaki MS, Abdel-Aleem A, Rosti RO (2009) Mutations in INPP5E, encoding inositol polyphosphate-5-phosphatase E, link phosphatidyl inositol-signaling to the ciliopathies. Nat Genet 41:1032-1036

116. Nigg EA, Stearns T (2011) The centrosome cycle: centriole biogenesis, duplication and inherent asymmetries. Nat Cell Biol 13:1154-1160

117. Kulaga HM, Leitch CC, Eichers ER, Badano JL, Lesemann A, Hoskins BE, Lupski JR, Beales PL, Reed RR, Katsanis N (2004) Loss of BBS proteins causes anosmia in humans and defects in olfactory cilia structure and function in the mouse. Nat Genet 36:994-998

118. Fath MA, Mullins RF, Searby C, Nishimura DY, Wei J, Rahmouni K, Davis RE, Tayeh MK, Andrews M, Yang B, Sigmund CD, Stone EM, Sheffield VC (2005) Mkks-null mice have a phenotype resembling Bardet-Biedl syndrome. Hum Mol Genet 14:1109-1118

119. Kim JC, Ou YY, Badano JL, Esmail MA, Leitch CC, Fiedrich E, Beales PL, Archibald JM, Katsanis N, Rattner JB, Leroux MR (2005) MKKS/BBS6, a divergent chaperonin-like protein linked to the obesity disorder Bardet-Biedl syndrome, is a novel centrosomal component required for cytokinesis. J Cell Sci 118:1007-1020

120. Robert A, Margall-Ducos G, Guidotti J-E, Brégerie O, Celati C, Bréchot C, Desdouets C (2007) The intraflagellar transport component IFT88/polaris is a centrosomal protein regulating G1-S transition in non-ciliated cells. J Cell Sci 120:628-637

121. Richards WG, Yoder BK, Isfort RJ, Detilleux PG, Foster C, Neilsen N, Woychik RP, Wilkinson JE (1996) Oval cell proliferation associated with the murine insertional mutation TgN737Rpw. Am J Pathol 149:1919-1930

122. Zhang Q, Davenport JR, Croyle MJ, Haycraft CJ, Yoder BK (2005) Disruption of IFT results in both exocrine and endocrine abnormalities in the pancreas of Tg737(orpk) mutant mice. Lab Invest 85:45-64

123. Qin H, Wang Z, Diener D, Rosenbaum J (2007) Intraflagellar transport protein 27 is a small G protein involved in cell-cycle control. Curr Biol 17:193-202

124. Wood CR, Wang Z, Diener D, Zones JM, Rosenbaum J, Umen JG (2012) IFT proteins accumulate during cell division and localize to the cleavage furrow in Chlamydomonas. PLoS One 7:e30729

125. Satir P, Mitchell DR, Jékely G (2008) How did the cilium evolve? Curr Top Dev Biol 85:63-82

126. Smith KR, Kieserman EK, Wang PI, Basten SG, Giles RH, Marcotte EM, Wallingford JB (2011) A role for central spindle proteins in cilia structure and function. Cytoskeleton 68:112-124

127. Plotnikova OV, Golemis EA, Pugacheva EN (2008) Cell cycle-dependent ciliogenesis and cancer. Cancer Res 68:2058-2061

128. Mikule K, Delaval B, Kaldis P, Jurcyzk A, Hergert P, Doxsey S (2007) Loss of centrosome integrity induces p38-p53-p21-dependent G1-S arrest. Nat Cell Biol 9:160-170

129. Plotnikova OV, Pugacheva EN, Golemis EA (2009) Primary cilia and the cell cycle. Methods Cell Biol 94:137-160

130. Pugacheva EN, Jablonski SA, Hartman TR, Henske EP, Golemis EA (2007) HEF1-dependent Aurora A activation induces disassembly of the primary cilium. Cell 129:1351-1363 
131. Kinzel D, Boldt K, Davis EE, Burtscher I, Trümbach D, Diplas B, Attié-Bitach T, Wurst W, Katsanis N, Ueffing M, Lickert H (2010) Pitchfork regulates primary cilia disassembly and left-right asymmetry. Dev Cell 19:66-77

132. Li Y, Bavarva JH, Wang Z, Guo J, Qian C, Thibodeau SN, Golemis EA, Liu W (2011) HEF1, a novel target of Wnt-signaling, promotes colonic cell migration and cancer progression. Oncogene 30:2633-2643

133. Lee KH, Johmura Y, Yu L-R, Park J-E, Gao Y, Bang JK, Zhou M, Veenstra TD, Yeon Kim B, Lee KS (2012) Identification of a novel Wnt5a-CK1 $\varepsilon$-Dvl2-Plk1mediated primary cilia disassembly pathway. EMBO J 31:3104-3117

134. Spalluto C, Wilson DI, Hearn T (2012) Nek2 localises to the distal portion of the mother centriole/basal body and is required for timely cilium disassembly at the G2/M transition. Eur J Cell Biol 91:675-686

135. Tsang WY, Bossard C, Khanna H, Peränen J, Swaroop A, Malhotra V, Dynlacht BD (2008) CP110 suppresses primary cilia formation through its interaction with CEP290, a protein deficient in human ciliary disease. Dev Cell 15:187-197

136. Spektor A, Tsang WY, Khoo D, Dynlacht BD (2007) Cep97 and CP110 suppress a cilia assembly program. Cell 130:678-690

137. Tsang WY, Spektor A, Luciano DJ, Indjeian VB, Chen Z, Salisbury JL, Sánchez I, Dynlacht BD (2006) CP110 cooperates with two calcium-binding proteins to regulate cytokinesis and genome stability. Mol Biol Cell 17:3423-3434

138. Humbert MC, Weihbrecht K, Searby CC, Li Y, Pope RM, Sheffield VC, Seo S (2012) ARL13B, PDE6D, and CEP164 form a functional network for INPP5E ciliary targeting. Proc Natl Acad Sci 109:19691-19696

139. Jackson PK (2011) Do cilia put brakes on the cell cycle? Nat Cell Biol 13:340-342

140. Kim S, Zaghloul NA, Bubenshchikova E, Oh EC, Rankin S, Katsanis N, Obara T, Tsiokas L (2011) Nde1-mediated inhibition of ciliogenesis affects cell cycle re-entry. Nat Cell Biol 13:351-360

141. Li A, Saito M, Chuang J-Z, Tseng Y-Y, Dedesma C, Tomizawa K, Kaitsuka T, Sung C-H (2011) Ciliary transition zone activation of phosphorylated Tctex-1 controls ciliary resorption, S-phase entry and fate of neural progenitors. Nat Cell Biol 13:402-411

142. Besschetnova TY, Kolpakova-Hart E, Guan Y, Zhou J, Olsen BR, Shah JV (2010) Identification of signaling pathways regulating primary cilium length and flow-mediated adaptation. Curr Biol 20:182-187

143. Wang W, Brautigan DL (2008) Phosphatase inhibitor 2 promotes acetylation of tubulin in the primary cilium of human retinal epithelial cells. BMC Cell Biol 9:62

144. Abdul-Majeed S, Nauli SM (2011) Dopamine receptor type 5 in the primary cilia has dual chemo- and mechano-sensory roles. Hypertension 58:325-331

145. Avasthi P, Marley A, Lin H, Gregori-Puigjane E, Shoichet BK, von Zastrow M, Marshall WF (2012) A chemical screen identifies class a G protein-coupled receptors as regulators of cilia. ACS Chem Biol 7:911-919

146. Haug K, Khan S, Fuchs S, König R (2000) OFD II, OFD VI, and Joubert syndrome manifestations in two sibs. Am J Med Genet 91:135-137

147. Brancati F, Dallapiccola B, Valente EM (2010) Joubert Syndrome and related disorders. Orphanet J Rare Dis 5:20

148. Beales PL, Reid HA, Griffiths MH, Maher ER, Flinter FA, Woolf AS (2000) Renal cancer and malformations in relatives of patients with Bardet-Biedl syndrome. Nephrol Dial Transplant 15:1977-1985

149. Hjortshøj TD, Grønskov K, Rosenberg T, Brøndum-Nielsen K, Olsen JH (2007) Risk for cancer in patients with Bardet-Biedl syndrome and their relatives. Am J Med Genet A 143A:1699-1702

150. García-Zaragoza E, Pérez-Tavarez R, Ballester A, Lafarga V, Jiménez-Reinoso A, Ramírez Á, Murillas R, Gallego MI (2012) Intraepithelial paracrine hedgehog-signaling induces the expansion of ciliated cells that express diverse progenitor cell markers in the basal epithelium of the mouse mammary gland. Dev Biol 372:28-44

151. Hassounah NB, Bunch TA, McDermott KM (2012) Molecular pathways: the role of primary cilia in cancer progression and therapeutics with a focus on hedgehog- signaling. Clin Cancer Res 18:2429-2435

152. Wood LD, Parsons DW, Jones S, Lin J, Sjöblom T, Leary RJ, Shen D, Boca SM, Barber T, Ptak J, Silliman N, Szabo S, Dezso Z, Ustyanksky V, Nikolskaya T, Nikolsky Y, Karchin R, Wilson PA, Kaminker JS, Zhang Z, Croshaw R, Willis J, Dawson D, Shipitsin M, Willson JKV, Sukumar S, Polyak K, Park BH, Pethiyagoda CL, Pant PVK, et al. (2007) The genomic landscapes of human breast and colorectal cancers. Science 318:1108-1113

153. Sjöblom T, Jones S, Wood LD, Parsons DW, Lin J, Barber TD, Mandelker D, Leary RJ, Ptak J, Silliman N, Szabo S, Buckhaults P, Farrell C, Meeh P, Markowitz SD, Willis J, Dawson D, Willson JKV, Gazdar AF, Hartigan J, Wu L,
Liu C, Parmigiani G, Park BH, Bachman KE, Papadopoulos N, Vogelstein B, Kinzler KW, Velculescu VE (2006) The consensus coding sequences of human breast and colorectal cancers. Science 314:268-274

154. Yuan K, Frolova N, Xie Y, Wang D, Cook L, Kwon Y-J, Steg AD, Serra R, Frost AR (2010) Primary cilia are decreased in breast cancer: analysis of a collection of human breast cancer cell lines and tissues. J Histochem Cytochem 58:857-870

155. McDermott KM, Liu BY, Tlsty TD, Pazour GJ (2010) Primary cilia regulate branching morphogenesis during mammary gland development. Curr Biol 20:731-737

156. Bowers AJ, Boylan JF (2004) Nek8, a NIMA family kinase member, is overexpressed in primary human breast tumors. Gene 328:135-142

157. Habbig S, Bartram MP, Sägmüller JG, Griessmann A, Franke M, Müller R-U, Schwarz R, Hoehne M, Bergmann C, Tessmer C, Reinhardt HC, Burst V, Benzing T, Schermer B (2012) The ciliopathy disease protein NPHP9 promotes nuclear delivery and activation of the oncogenic transcriptional regulator TAZ. Hum Mol Genet 21:5528-5538

158. Kim J, Dabiri S, Seeley ES (2011) Primary cilium depletion typifies cutaneous melanoma in situ and malignant melanoma. PLoS One 6:e27410

159. Seeley ES, Carrière C, Goetze T, Longnecker DS, Korc M (2009) Pancreatic cancer and precursor pancreatic intraepithelial neoplasia lesions are devoid of primary cilia. Cancer Res 69:422-430

160. Egeberg DL, Lethan M, Manguso R, Schneider L, Awan A, Jørgensen TS, Byskov AG, Pedersen LB, Christensen ST (2012) Primary cilia and aberrant cell-signaling in epithelial ovarian cancer. Cilia 1:15

161. Bezginov A, Clark GW, Charlebois RL, Dar V-U-N, Tillier ERM (2012) Coevolution reveals a network of human proteins originating with multicellularity. Mol Biol Evol 30:332-346

162. Basten SG, Davis EE, Gillis AJM, van Rooijen E, Stoop H, Babala N, Logister I, Heath ZG, Jonges TN, Katsanis N, Voest E, van Eeden FJ, Medema RH, Ketting RF, Schulte-Merker S, Looijenga LHJ, Giles RH (2013) Mutations in LRRC50 predispose zebrafish and humans to seminomas. PLoS Genet 9: e1003384

163. Santos N, Reiter JF (2008) Building it up and taking it down: the regulation of vertebrate ciliogenesis. Dev Dyn 237:1972-1981

164. Mans DA, Voest EE, Giles RH (2008) All along the watchtower: is the cilium a tumor suppressor organelle? BBA - Reviews on Cancer 1786:114-125

165. Wong SY, Seol AD, So P-L, Ermilov AN, Bichakjian CK, Epstein EH, Dlugosz AA, Reiter JF (2009) Primary cilia can both mediate and suppress hedgehog pathway-dependent tumorigenesis. Nat Med 15:1055-1061

166. Han Y-G, Kim HJ, Dlugosz AA, Ellison DW, Gilbertson RJ, Alvarez-Buylla A (2009) Dual and opposing roles of primary cilia in medulloblastoma development. Nat Med 15:1062-1065

167. Toftgård R (2009) Two sides to cilia in cancer. Nat Med 15:994-996

168. Scales SJ, de Sauvage FJ (2009) Mechanisms of hedgehog pathway activation in cancer and implications for therapy. Trends Pharmacol Sci 30:303-312

169. Bonsib SM (2009) Renal cystic diseases and renal neoplasms: a mini-review. Clin J Am Soc Nephrol 4:1998-2007

170. Rookmaaker MB, van Gerven HAJM, Goldschmeding R, Boer WH (2012) Solid renal tumors of collecting duct origin in patients on chronic lithium therapy. Clin Kidney J 5:412-415

171. Takahashi M, Yang XJ, Sugimura J, Backdahl J, Tretiakova M, Qian C-N, Gray SG, Knapp R, Anema J, Kahnoski R, Nicol D, Vogelzang NJ, Furge KA, Kanayama H, Kagawa S, Teh BT (2003) Molecular subclassification of kidney tumors and the discovery of new diagnostic markers. Oncogene 22:68106818

172. Klomp JA, Petillo D, Niemi NM, Dykema KJ, Chen J, Yang XJ, Sääf A, Zickert P, Aly M, Bergerheim U, Nordenskjöld M, Gad S, Giraud S, Denoux Y, Yonneau L, Méjean A, Vasiliu V, Richard S, MacKeigan JP, Teh BT, Furge KA (2010) Birt-Hogg-Dubé renal tumors are genetically distinct from other renal neoplasias and are associated with up-regulation of mitochondrial gene expression. BMC Med Genomics 3:59

173. Yusenko MV (2010) Molecular pathology of chromophobe renal cell carcinoma: a review. Int J Urol 17:592-600

174. Yusenko MV (2010) Molecular pathology of renal oncocytoma: a review. Int J Urol 17:602-612

175. Schraml P, Frew IJ, Thoma CR, Boysen G, Struckmann K, Krek W, Moch H (2008) Sporadic clear cell renal cell carcinoma but not the papillary type is characterized by severely reduced frequency of primary cilia. Mod Pathol 22:31-36 
176. Basten SG, Willekers S, Vermaat J, Slaats G (2013) Reduced cilia frequencies in human renal cell carcinomas versus neighboring parenchymal tissue. Cilia 2:2

177. Gemmill RM, West JD, Boldog F, Tanaka N, Robinson L, Smith DI, Li F, Drabkin HA (1998) The hereditary renal cell carcinoma 3;8 translocation fuses FHIT to a patched-related gene, TRC8. Proc Natl Acad Sci USA 95:9572-9577

178. Adam MP, Frantzen C, Links TP, Giles RH (2000) von Hippel-Lindau Disease

179. Moore LE, Nickerson ML, Brennan P, Toro JR, Jaeger E, Rinsky J, Han SS, Zaridze D, Matveev V, Janout V, Kollarova H, Bencko V, Navratilova M, Szeszenia-Dabrowska N, Mates D, Schmidt LS, Lenz P, Karami S, Linehan WM, Merino M, Chanock S, Boffetta P, Chow W-H, Waldman FM, Rothman N (2011) von Hippel-Lindau (VHL) inactivation in sporadic clear cell renal cancer: associations with germline VHL polymorphisms and etiologic risk factors. PLoS Genet 7:e1002312

180. Kaelin WG (2002) Molecular basis of the VHL hereditary cancer syndrome. Nat Rev Cancer 2:673-682

181. Kim WY, Safran M, Buckley MRM, Ebert BL, Glickman J, Bosenberg M, Regan M, Kaelin WG (2006) Failure to prolyl hydroxylate hypoxia-inducible factor alpha phenocopies VHL inactivation in vivo. EMBO J 25:4650-4662

182. Schermer B, Ghenoiu C, Bartram M, Müller R-U, Kotsis F, Höhne M, Kühn W, Rapka M, Nitschke R, Zentgraf H, Fliegauf M, Omran H, Walz G, Benzing T (2006) The von Hippel-Lindau tumor suppressor protein controls ciliogenesis by orienting microtubule growth. J Cell Biol 175:547-554

183. Thoma CR, Frew IJ, Hoerner CR, Montani M, Moch H, Krek W (2007) pVHL and GSK3beta are components of a primary cilium-maintenance signaling network. Nat Cell Biol 9:588-595

184. Frew IJ, Thoma CR, Georgiev S, Minola A, Hitz M, Montani M, Moch H, Krek W (2008) pVHL and PTEN tumor suppressor proteins cooperatively suppress kidney cyst formation. EMBO J 27:1747-1757

185. Thoma CR, Toso A, Gutbrodt KL, Reggi SP, Frew IJ, Schraml P, Hergovich A, Moch H, Meraldi P, Krek W (2009) VHL loss causes spindle misorientation and chromosome instability. Nat Cell Biol 11:994-1001

186. Hartman TR, Liu D, Zilfou JT, Robb V, Morrison T, Watnick T, Henske EP (2008) The tuberous sclerosis proteins regulate formation of the primary cilium via a rapamycin-insensitive and polycystin 1-independent pathway. Hum Mol Genet 18:151-163

187. Crino PB, Nathanson KL, Henske EP (2006) The tuberous sclerosis complex. N Engl J Med 355:1345-1356

188. Dabora SL, Jozwiak S, Franz DN, Roberts PS, Nieto A, Chung J, Choy YS, Reeve MP, Thiele E, Egelhoff JC, Kasprzyk-Obara J, Domanska-Pakiela D, Kwiatkowski DJ (2001) Mutational analysis in a cohort of 224 tuberous sclerosis patients indicates increased severity of TSC2, compared with TSC1, disease in multiple organs. Am J Hum Genet 68:64-80

189. Wilson C (2005) A mouse model of tuberous sclerosis 1 showing background specific early post-natal mortality and metastatic renal cell carcinoma. Hum Mol Genet 14:1839-1850

190. Kobayashi TT, Minowa OO, Sugitani YY, Takai SS, Mitani HH, Kobayashi EE, Noda TT, Hino OO (2001) A germ-line Tsc1 mutation causes tumor development and embryonic lethality that are similar, but not identical to, those caused by Tsc2 mutation in mice. Proc Natl Acad Sci USA 98:8762-8767

191. Kobayashi T, Minowa O, Kuno J, Mitani H, Hino O, Noda T (1999) Renal carcinogenesis, hepatic hemangiomatosis, and embryonic lethality caused by a germ-line Tsc2 mutation in mice. Cancer Res 59:1206-1211

192. DiBella LM, Park A, Sun Z (2009) Zebrafish Tsc1 reveals functional interactions between the cilium and the TOR pathway. Hum Mol Genet 18:595-606

193. Yuan S, Li J, Diener DR, Choma MA, Rosenbaum JL, Sun Z (2012) Target-ofrapamycin complex 1 (Torc1)-signaling modulates cilia size and function through protein synthesis regulation. Proc Natl Acad Sci 109:2021-2026

194. Lim DHK, Rehal PK, Nahorski MS, Macdonald F, Claessens T, van Geel M, Gijezen L, Gille JJP, Giraud S, Richard S, van Steensel M, Menko FH, Maher ER (2010) A new locus-specific database (LSDB) for mutations in the folliculin (FLCN) gene. Hum Mutat 31:E1043-E1051

195. Tee AR, Pause A (2012) Birt-Hogg-Dubé: tumor suppressor function and signaling dynamics central to folliculin. Fam Cancer. Epub ahead of print

196. Pavlovich CP, Walther MM, Eyler RA, Hewitt SM, Zbar B, Linehan WM, Merino MJ (2002) Renal tumors in the Birt-Hogg-Dubé syndrome. Am J Surg Pathol 26:1542-1552

197. Baba M, Furihata M, Hong SB, Tessarollo L, Haines DC, Southon E, Patel V, Igarashi P, Alvord WG, Leighty R, Yao M, Bernardo M, lleva L, Choyke P, Warren MB, Zbar B, Linehan WM, Schmidt LS (2008) Kidney-targeted Birt-Hogg-Dubé gene inactivation in a mouse model: Erk1/2 and Akt-mTOR activation, cell hyperproliferation, and polycystic kidneys. JNCI 100:140-154
198. Proceedings of the First International Cilia in Development and Disease Scientific Conference 2012. http://www.ciliajournal.com/supplements/1/S1

199. Hasumi Y, Baba M, Ajima R, Hasumi H, Valera VA, Klein ME, Haines DC, Merino MJ, Hong S-B, Yamaguchi TP, Schmidt LS, Linehan WM (2009) Homozygous loss of BHD causes early embryonic lethality and kidney tumor development with activation of mTORC1 and mTORC2. Proc Natl Acad Sci 106:18722-18727

200. Hartman TR, Nicolas E, Klein-Szanto A, Al-Saleem T, Cash TP, Simon MC, Henske EP (2009) The role of the Birt-Hogg-Dubé protein in mTOR activation and renal tumorigenesis. Oncogene 28:1594-1604

201. Ollila S, Mäkelä TP (2011) The tumor suppressor kinase LKB1: lessons from mouse models. J Mol Cell Biol 3:330-340

202. van der Velden YU, Wang L, Zevenhoven J, van Rooijen E, van Lohuizen M, Giles RH, Clevers H, Haramis A-PG (2011) The serine-threonine kinase LKB1 is essential for survival under energetic stress in zebrafish. Proc Natl Acad Sci 108:4358-4363

203. Boehlke C, Kotsis F, Patel V, Braeg S, Voelker H, Bredt S, Beyer T, Janusch $H_{\text {, }}$ Hamann C, Gödel M, Müller K, Herbst M, Hornung M, Doerken M, Köttgen M, Nitschke R, Igarashi P, Walz G, Kuehn EW (2010) Primary cilia regulate mTORC1 activity and cell size through Lkb1. Nat Cell Biol 12:1115-1122

204. Wei C, Bhattaram VK, Igwe JC, Fleming E, Tirnauer JS (2012) The LKB1 tumor suppressor controls spindle orientation and localization of activated AMPK in mitotic epithelial cells. PLoS One 7:e41118

205. Snape K, Hanks S, Ruark E, Barros-Núñez P, Elliott A, Murray A, Lane AH, Shannon N, Callier P, Chitayat D, Clayton-Smith J, FitzPatrick DR, Gisselsson D, Jacquemont S, Asakura-Hay K, Micale MA, Tolmie J, Turnpenny PD, Wright M, Douglas J, Rahman N (2011) Mutations in CEP57 cause mosaic variegated aneuploidy syndrome. Nat Genet 43:527-529

206. Hanks S, Coleman K, Reid S, Plaja A, Firth H, FitzPatrick D, Kidd A, Méhes K, Nash R, Robin N, Shannon N, Tolmie J, Swansbury J, Irrthum A, Douglas J, Rahman N (2004) Constitutional aneuploidy and cancer predisposition caused by biallelic mutations in BUB1B. Nat Genet 36:1159-1161

207. Miyamoto T, Porazinski S, Wang H, Borovina A, Ciruna B, Shimizu A, Kajii T, Kikuchi A, Furutani-Seiki M, Matsuura S (2011) Insufficiency of BUBR1, a mitotic spindle checkpoint regulator, causes impaired ciliogenesis in vertebrates. Hum Mol Genet 20:2058-2070

208. Suijkerbuijk SJE, van Osch MHJ, Bos FL, Hanks S, Rahman N, Kops GJPL (2010) Molecular causes for BUBR1 dysfunction in the human cancer predisposition syndrome mosaic variegated aneuploidy. Cancer Res 70:4891-4900

209. Parren LJMT, Frank J (2011) Hereditary tumor syndromes featuring basal cell carcinomas. Br J Dermatol 165:30-34

210. Epstein EH (2008) Basal cell carcinomas: attack of the hedgehog. Nat Rev Cancer 8:743-754

211. Gómez García EB, Knoers NVAM (2009) Gardner's syndrome (familial adenomatous polyposis): a cilia-related disorder. Lancet Oncol 10:727-735

212. Jimbo T, Kawasaki Y, Koyama R, Sato R, Takada S, Haraguchi K, Akiyama T (2002) Identification of a link between the tumor suppressor APC and the kinesin superfamily. Nat Cell Biol 4:323-327

213. Aoki K, Taketo MM (2007) Adenomatous polyposis coli (APC): a multi-functional tumor suppressor gene. J Cell Sci 120:3327-3335

214. Jaulin F, Kreitzer G (2010) KIF17 stabilizes microtubules and contributes to epithelial morphogenesis by acting at MT plus ends with EB1 and APC. J Cell Biol 190:443-460

215. Moniz L, Dutt P, Haider N, Stambolic V (2011) Nek family of kinases in cell cycle, checkpoint control and cancer. Cell Div 6:1-25

216. Zalli D, Bayliss R, Fry AM (2012) The Nek8 protein kinase, mutated in the human cystic kidney disease nephronophthisis, is both activated and degraded during ciliogenesis. Hum Mol Genet 21:1155-1171

217. Vogler C, Homan S, Pung A, Thorpe C, Barker J, Birkenmeier EH, Upadhya P (1999) Clinical and pathologic findings in two new allelic murine models of polycystic kidney disease. J Am Soc Nephrol 10:2534-2539

218. Mahjoub MR, Trapp ML, Quarmby LM (2005) NIMA-related kinases defective in murine models of polycystic kidney diseases localize to primary cilia and centrosomes. J Am Soc Nephrol 16:3485-3489

219. Thiel C, Kessler K, Giessl A, Dimmler A, Shalev SA, von der Haar S, Zenker M, Zahnleiter D, Stöss H, Beinder E, Abou Jamra R, Ekici AB, Schröder-Kreß N, Aigner T, Kirchner T, Reis A, Brandstätter JH, Rauch A (2011) NEK1 mutations cause short-rib polydactyly syndrome type Majewski. Am J Hum Genet 88:106-114

220. Bettencourt-Dias M, Hildebrandt F, Pellman D, Woods G, Godinho SA (2011) Centrosomes and cilia in human disease. Trends Genet 27:307-315 
221. Aboualaiwi WA, Ratnam S, Booth RL, Shah JV, Nauli SM (2011) Endothelial cells from humans and mice with polycystic kidney disease are characterized by polyploidy and chromosome segregation defects through survivin downregulation. Hum Mol Genet 20:354-367

222. Majumder S, Fisk HA (2013) VDAC3 and Mps1 negatively regulate ciliogenesis. Cell Cycle 12:1-10

223. Haraguchi K, Hayashi T, Jimbo T, Yamamoto T, Akiyama T (2006) Role of the kinesin-2 family protein, KIF3, during mitosis. J Biol Chem 281:4094-4099

224. Teng J, Rai T, Tanaka Y, Takei Y, Nakata T, Hirasawa M, Kulkarni AB, Hirokawa N (2005) The KIF3 motor transports N-cadherin and organizes the developing neuroepithelium. Nat Cell Biol 7:474-482

225. Sperka T, Wang J, Rudolph KL (2012) DNA damage checkpoints in stem cells, ageing and cancer. Nat Rev Mol Cell Biol 13:579-590

226. Chaki M, Airik R, Ghosh AK, Giles RH, Chen R, Slaats GG, Wang H, Hurd TW, Zhou W, Cluckey A, Gee HY, Ramaswami G, Hong C-J, Hamilton BA, Červenka I, Ganji RS, Bryja V, Arts HH, van Reeuwijk J, Oud MM, Letteboer SJF, Roepman R, Husson H, Ibraghimov-Beskrovnaya O, Yasunaga T, Walz G, Eley L, Sayer JA, Schermer B, Liebau MC, et al. (2012) Exome capture reveals ZNF423 and CEP164 mutations, linking renal ciliopathies to DNA damage response-signaling. Cell 150:533-548

227. Otto EA, Hurd TW, Airik R, Chaki M, Zhou W, Stoetzel C, Patil SB, Levy S, Ghosh AK, Murga-Zamalloa CA, van Reeuwijk J, Letteboer SJF, Sang L, Giles RH, Liu Q Coene KLM, Estrada-Cuzcano A, Collin RWJ, McLaughlin HM, Held S, Kasanuki JM, Ramaswami G, Conte J, Lopez I, Washburn J, MacDonald J, Hu J, Yamashita Y, Maher ER, Guay-Woodford LM, et al. (2010) Candidate exome capture identifies mutation of SDCCAG8 as the cause of a retinal-renal ciliopathy. Nat Genet 42:840-850

228. Graser S, Stierhof Y-D, Lavoie SB, Gassner OS, Lamla S, Le Clech M, Nigg EA (2007) Cep164, a novel centriole appendage protein required for primary cilium formation. J Cell Biol 179:321-330

229. Saladino C, Bourke E, Conroy PC, Morrison CG (2009) Centriole separation in DNA damage-induced centrosome amplification. Environ Mol Mutagen 50:725-732

230. Conroy PC, Saladino C, Dantas TJ, Lalor P, Dockery P, Morrison CG (2012) C-NAP1 and rootletin restrain DNA damage-induced centriole splitting and facilitate ciliogenesis. Cell Cycle 11:3769-3778

231. Christensen ST, Pedersen SF, Satir P, Veland IR, Schneider L (2008) The primary cilium coordinates signaling pathways in cell cycle control and migration during development and tissue repair. Curr Top Dev Biol 85:261-301

232. Jones TJ, Adapala RK, Geldenhuys WJ, Bursley C, Aboualaiwi WA, Nauli SM, Thodeti CK (2012) Primary cilia regulates the directional migration and barrier integrity of endothelial cells through the modulation of Hsp27 dependent actin cytoskeletal organization. J Cell Physiol 227:70-76

233. Simpson KJ, Selfors LM, Bui J, Reynolds A, Leake D, Khvorova A, Brugge JS (2008) Identification of genes that regulate epithelial cell migration using an siRNA screening approach. Nat Cell Biol 10:1027-1038

234. Hanahan D, Weinberg RA (2011) Hallmarks of cancer: the next generation. Cell 144:646-674

235. Zhang D, Sun L, Xian W, Liu F, Ling G, Xiao L, Liu Y, Peng Y, Haruna Y, Kanwar YS (2010) Low-dose paclitaxel ameliorates renal fibrosis in rat UUO model by inhibition of TGF-beta/Smad activity. Lab Invest 90:436-447

doi:10.1186/2046-2530-2-6

Cite this article as: Basten and Giles: Functional aspects of primary cilia in signaling, cell cycle and tumorigenesis. Cilia 2013 2:6.

\section{Submit your next manuscript to BioMed Central and take full advantage of:}

- Convenient online submission

- Thorough peer review

- No space constraints or color figure charges

- Immediate publication on acceptance

- Inclusion in PubMed, CAS, Scopus and Google Scholar

- Research which is freely available for redistribution 